University of Wollongong

Research Online

Australian Institute for Innovative Materials -

Papers

Australian Institute for Innovative Materials

$1-1-2018$

Porous Zr2SC-carbon composite microspheres: Possible radiation tolerant sorbents and transmutation hosts for technetium-99

Nicholas Scales

ANSTO,ns112@uowmail.edu.au

Jun Chen

University of Wollongong, junc@uow.edu.au

Robert Aughterson

ANSTO

Inna Karatchevtseva

ANSTO

Attila Stopic

ANSTO

See next page for additional authors

Follow this and additional works at: https://ro.uow.edu.au/aiimpapers

Part of the Engineering Commons, and the Physical Sciences and Mathematics Commons

Research Online is the open access institutional repository for the University of Wollongong. For further information contact the UOW Library: research-pubs@uow.edu.au 


\title{
Porous Zr2SC-carbon composite microspheres: Possible radiation tolerant sorbents and transmutation hosts for technetium-99
}

\author{
Abstract \\ The preparation, characteristics and adsorption properties of novel porous carbon-ceramic composite \\ microspheres are presented. The composites were synthesised by a simple ion exchange process \\ involving the cationic Zr tetramer and commonly-available macroporous sulphonated polystyrene- \\ divinylbenzene cation exchange resins, with subsequent carbothermal reduction at $1350^{\circ} \mathrm{C}$. The \\ materials were extensively characterised with respect to composition, chemical structure and porosity. \\ Carbothermal reduction of the $\mathrm{Zr}$-loaded templates resulted in formation of crystallites of the MAX phase \\ zirconium sulphide carbide ( $\mathrm{Zr} 2 \mathrm{SC}$ ) embedded within a highly microporous carbon framework with a \\ macroporous secondary structure inherited from the resin template. Despite the high BET surface areas \\ of the Zr 2 SC-carbon composite microspheres (in some cases, greater than $600 \mathrm{~m} 2 \mathrm{~g} \mathrm{-1}$ ), they are \\ extremely mechanically robust. The microspheres displayed high adsorption selectivity for oxoanions \\ relative to cationic solution species, including perrhenate ( $\mathrm{ReO} 4-$ ), a pertechnetate ( $\mathrm{TcO} 4$ - ) surrogate. \\ Accumulation of ReO 4 - on the Zr 2 SC particles was unequivocally demonstrated by elemental mapping. \\ Such materials are potential candidates as combined 99 Tc sorbents and reusable transmutation hosts.

\section{Disciplines} \\ Engineering | Physical Sciences and Mathematics

\section{Publication Details} \\ Scales, N., Chen, J., Aughterson, R. D., Karatchevtseva, I., Stopic, A., Lumpkin, G. R. \& Luca, V. (2018). \\ Porous Zr2SC-carbon composite microspheres: Possible radiation tolerant sorbents and transmutation \\ hosts for technetium-99. Microporous and Mesoporous Materials, 259 67-78.

\section{Authors} \\ Nicholas Scales, Jun Chen, Robert Aughterson, Inna Karatchevtseva, Attila Stopic, Gregory R. Lumpkin, \\ and Vittorio Luca
}




\section{Porous $\mathrm{Zr}_{2} \mathrm{SC}$-carbon composite microspheres: possible radiation}

\section{2 tolerant sorbents and transmutation hosts for technetium-99}

3 Nicholas Scales $^{\mathrm{a},}$, , Jun Chen ${ }^{\mathrm{b}}$, Robert D. Aughterson ${ }^{\mathrm{a}}$, Inna Karatchevtseva ${ }^{\mathrm{a}}$, Attila Stopic ${ }^{\mathrm{a}}$,

4 Gregory R. Lumpkin ${ }^{\mathrm{a}}$ and Vittorio Lucac, *

$5 \quad{ }^{a}$ Australian Nuclear Science and Technology Organisation, Locked Bag 2001, Kirrawee

6 DC, New South Wales, 2232, Australia

$7 \quad$ bntelligent Polymer Research Institute, ARC Centre of Excellence for Electromaterials

8 Science, Australian Institute of Innovative Materials, University of Wollongong, Innovation

9 Campus, North Wollongong, NSW 2522, Australia

10 'Programa Nacional de Gestión de Residuos Radiactivos, Comisión Nacional de Energía

11 Atómica, Centro Atómico Constituyentes, Av. General, Paz 1499, 1650 San Martin,

12 Provincia de Buenos Aires, República Argentina

13 *Corresponding authors (nsz@ansto.gov.au; vluca@cnea.gov.ar)

15 Abstract

16 The preparation, characteristics and adsorption properties of novel porous carbon-ceramic

17 composite microspheres are presented. The composites were synthesised by a simple ion exchange process involving the cationic $\mathrm{Zr}$ tetramer and commonly-available macroporous sulphonated polystyrene-divinylbenzene cation exchange resins, with subsequent carbothermal reduction at $1350{ }^{\circ} \mathrm{C}$. The materials were extensively characterised with respect

21 to composition, chemical structure and porosity. Carbothermal reduction of the Zr-loaded templates resulted in formation of crystallites of the MAX phase zirconium sulphide carbide $\left(\mathrm{Zr}_{2} \mathrm{SC}\right)$ embedded within a highly microporous carbon framework with a macroporous 
secondary structure inherited from the resin template. Despite the high BET surface areas of the $\mathrm{Zr}_{2} \mathrm{SC}$-carbon composite microspheres (in some cases, greater than $600 \mathrm{~m}^{2} \mathrm{~g}^{-1}$ ), they are extremely mechanically robust. The microspheres displayed high adsorption selectivity for oxoanions relative to cationic solution species, including perrhenate $\left(\mathrm{ReO}_{4}^{-}\right)$, a pertechnetate $\left(\mathrm{TcO}_{4}{ }^{-}\right)$surrogate. Accumulation of $\mathrm{ReO}_{4}{ }^{-}$on the $\mathrm{Zr}_{2} \mathrm{SC}$ particles was unequivocally demonstrated by elemental mapping. Such materials are potential candidates as combined ${ }^{99} \mathrm{Tc}$ sorbents and reusable transmutation hosts.

Keywords: technetium; adsorption; MAX phase; carbonization; ion exchange resin

\section{Introduction}

34 Nuclear power generation has produced as by-products, large inventories of fissile and burnable extremely long-lived isotopes of the transuranic elements $(\mathrm{Np}, \mathrm{Pu}, \mathrm{Am}$ and $\mathrm{Cm})$ as well as long-lived fission products, including, but not limited to, ${ }^{99} \mathrm{Tc},{ }^{93} \mathrm{Zr},{ }^{135} \mathrm{Cs},{ }^{107} \mathrm{Pd}$ and ${ }^{129}$ I) $[1,2]$. The above mentioned transuranics together are responsible for long-term decay heat generation and radiotoxicity. Along with waste partitioning, one means of reducing waste volume and long-term radiotoxicity that has been receiving serious consideration, is transmutation via neutron irradiation, in order to convert long-lived radionuclides into much shorter-lived ones. With respect to the latter initiative, the Gen IV International Forum has selected next-generation reactor types for further $\mathrm{R} \& \mathrm{D}$, with a goal of a closed nuclear fuel cycle incorporating total actinide burn-up [3]. The irradiation matrix is often conceived as a radiation-tolerant ceramic phase incorporating the Minor Actinides $(\mathrm{Np}, \mathrm{Am}, \mathrm{Cm})$ in a solid solution or mixture in the form of a fully-dense monolith, viz., Inert Matrix Fuel (IMF). The demands on a host matrix in terms of materials properties can best be described as extreme 
and include very high melting point, thermal conductivity, chemical and radiation stability as well as low neutron cross-section. Candidate host matrices include oxide, nitride and carbide ceramics, as well as other mineral-based structures such as $\mathrm{Y}_{3} \mathrm{Al}_{2} \mathrm{O}_{5}$ (yttrium aluminium garnet or YAG) and spinel $\left(\mathrm{MgSi}_{2} \mathrm{O}_{4}\right)$ [4]. For instance in the ECRIX-H experiment utilising an Am-containing $\mathrm{MgO}$ matrix, a transmutation rate of $95 \%$ was achieved following irradiation in the Phénix reactor with $29 \%$ fast flux for 318 effective full power days [5]. Nevertheless many technical challenges need to be overcome before Minor Actinide transmutation can be implemented. Of the long-lived fission products, the transmutation of ${ }^{99} \mathrm{Tc},\left({ }^{99} \mathrm{Tc}+\mathrm{n} \rightarrow{ }^{100} \mathrm{Ru}+\beta^{-}\right)$is generally considered technically feasible, although it has received much less attention $[1,6]$. The current work attempts to address target materials for 57 the transmutation of ${ }^{99} \mathrm{Tc}$.

Conventional IMFs are dense single- or two-phase monolithic materials. A single phase system would consist of the radionuclide to be transmuted being incorporated substitutionally within the crystal structure of a ceramic phase. In two-phase systems such as ceramic-ceramic (cercer) or cermic-metallic (cermet) composites the radionuclide is incorporated within a separate phase. For instance, the ECRIX matrices are cercers since they initially consist of $\mathrm{AmO}_{1.62}$ particles dispersed in $\mathrm{MgO}$ [5]. However, most nuclear fuels have limited burn-up capabilities, and only a fraction (say up to $30 \%$ ) of the transuranics can be burned before the fuel reaches its damage limits and needs to be reprocessed and refabricated. Therefore reprocessability is an important criterion in determining the utility of a transmutation matrix or fuel. In contrast, wasteform matrices for the immobilization of transuranics are required be extremely insoluble under a wide range of potential geological conditions.

69 As an alternative to fully-dense transmutation targets, the dissolution of which might be difficult, we suggested in our previous work that the aforementioned candidate host materials 
prepared in suitable porous forms could be the basis for radiation-tolerant and reusable targets, but with generation of less solid waste [7]. Porous monoliths would have several potential advantages. First, fission gas generation would be less likely to cause swelling and cracking since the gas could easily be accommodated within pores. Second, high energy fragments resulting from neutronic reactions would always reside near pores. Third, the reactants and products could be introduced and removed by simple solid-liquid phase adsorption and desorption, respectively; and if the materials were prepared in granular forms, could readily lend themselves to column chromatography. Such materials might also find application in the production of nuclear medicines, wherein the easy recycling of costly isotopically-enriched target elements would be desirable to minimise production costs. To this end, we had produced carbon-zirconium carbide composite porous monoliths based on a porous polyacrylonitrile (PAN) sphere template, with demonstrated reversible adsorption of Mo. As one member of the aforementioned candidate transmutation matrices, zirconium carbide $\left(\mathrm{ZrC}_{1-\mathrm{x}}\right)$ possesses excellent thermal conductivity, radiation tolerance and thermal stability [8].

Sorbents for ${ }^{99} \mathrm{Tc}$ have generally included diverse materials such activated carbon, natural minerals, synthetic inorganics and ion exchange resins [9-22]. Metal-Organic Frameworks (MOFs) have also been highlighted for their potential for ${ }^{99} \mathrm{Tc}$ removal and sequestration [2326]. There have been few examples of porous granular materials for ${ }^{99} \mathrm{Tc}$ capture and especially ones well-suited to demanding radiation environments [27]. However, recently Shu and co-workers reported ion-imprinted inorganic-based magnetic microspheres exhibiting selectivity for $\mathrm{ReO}_{4}{ }^{-}\left({ }^{99} \mathrm{TcO}_{4}{ }^{-}\right.$surrogate) even in moderately acidic conditions [28]. carbides and nitrides; where $\mathrm{M}$ is an early transition metal; $A$ is one of the elements in groups 
95 13-16; and $X$ is $\mathrm{C}$ and/or N [29, 30]. Due to their oxidation resistance and other properties

96 there has been considerable interest in their potential as nuclear structural materials. They are

97 normally prepared at high temperatures under reducing conditions and are usually obtained as

98 dense monoliths of little use as adsorbents. However, it has been demonstrated that

99 exfoliation of the MAX phases can yield two-dimensional MXenes (analogous to graphene)

100 with cation intercalation properties [31, 32]. In this work, we report new porous composites

101 containing the $\mathrm{Zr}_{2} \mathrm{SC}$ MAX phase, which were fabricated by a straightforward ion exchange-

102 based procedure promoting intimate contact between cationic $\mathrm{Zr}$ and polymeric organic

103 cation exchange resins. The latter serve as both porous structural templates and reactive

104 carbon sources, for in situ carbide formation via carbothermal reduction. Although metal-

105 loaded ion exchange resins have been employed as precursors for a diverse range of carbon

106 composites with ceramics and metals [33-44], to date this synthetic strategy has only been

107 applied to produce carbides of $\mathrm{U}$ and $\mathrm{Si}[45,46]$.

108 The objective of the current work was to produce novel porous microspheres, which could

109 conceivably be utilised as radiation-tolerant sorbents for the selective capture of ${ }^{99} \mathrm{Tc}$ and its

110 subsequent transmutation. We detail the synthesis of these materials; determine their

111 compositions as well as their chemical and physical structural characteristics; and investigate

112 their adsorption properties. 


\section{Experimental}

\subsection{Materials}

116 All chemical reagents including strong cation exchange resins were used as received without

117 further purification. Dowex ${ }^{\circledR}$ DR-2030 H, Amberlyst ${ }^{\circledR} 15 \mathrm{H}$, Dowex ${ }^{\circledR}$ 50WX2 H and

118 Amberlite ${ }^{\circledR} \mathrm{IR} 120 \mathrm{H}$ and $\mathrm{ZrOCl}_{2} .8 \mathrm{H}_{2} \mathrm{O}$ (98\%) were sourced from Sigma Aldrich, Australia.

119 Duolite ${ }^{\circledR}$ C $255 \mathrm{H}$ was obtained from Dia-prosim Limited, UK, while $\mathrm{NaReO}_{4}$ (99.9\%) was

120 obtained from Strem Chemicals, USA. Trace metal analytical grade $69 \% \mathrm{HNO}_{3}$ was sourced

121 from Seastar Chemicals Inc, Canada and Merck, Australia; and analytical grade $50 \mathrm{wt} \%$

$122 \mathrm{NaOH}$ solution was procured from Fluka Chemicals, Australia. A custom multi-element

123 standard $\left(2 \% \mathrm{HNO}_{3}\right.$ matrix, $>99.96 \%$ purity) was supplied by High Purity Standards, USA.

124 This solution was $10 \mathrm{mg} \mathrm{L}^{-1}$ with respect to each element and included $\mathrm{Al}, \mathrm{As}, \mathrm{Ba}, \mathrm{Be}, \mathrm{B}, \mathrm{Cd}$,

$125 \mathrm{Ca}, \mathrm{Ce}, \mathrm{Cs}, \mathrm{Cr}, \mathrm{Co}, \mathrm{Cu}, \mathrm{Dy}, \mathrm{Er}, \mathrm{Eu}, \mathrm{Gd}, \mathrm{Ga}, \mathrm{Ho}, \mathrm{Fe}, \mathrm{La}, \mathrm{Pb}, \mathrm{Lu}, \mathrm{Mg}, \mathrm{Mn}, \mathrm{Nd}, \mathrm{Ni}, \mathrm{P}, \mathrm{K}, \mathrm{Pr}$,

$126 \mathrm{Re}, \mathrm{Rb}, \mathrm{Sm}, \mathrm{Se}, \mathrm{Na}, \mathrm{Sr}, \mathrm{Tl}, \mathrm{Tm}, \mathrm{U}, \mathrm{V}, \mathrm{Yb}$ and $\mathrm{Zn}$. Instrument-grade air and $3.5 \mathrm{~mol} \% \mathrm{H}_{2}$ in

127 Ar gas mix were both produced by Coregas, Australia. Milli-Q ${ }^{\circledR}$ water $(18.2 \mathrm{M} \Omega . \mathrm{cm})$ was

128 used in all experiments.

\section{$129 \quad 2.2 \quad$ Synthesis}

\section{$130 \quad$ 2.2.1 Nomenclature}

131 Zirconium-loaded resins were named $\mathrm{ZrCX}-1$ to -5 to indicate the substrates used; these

132 were: macroporous resins Dowex ${ }^{\circledR}$ DR-2030 and Amberlyst ${ }^{\circledR} 15$ (ZrCX-1 and -2,

133 respectively) and gel resins Dowex ${ }^{\circledR}$ 50WX2, Amberlite ${ }^{\circledR}$ IR-120 and Duolite ${ }^{\circledR}$ C255 (ZrCX- 
1343 to -5 , respectively). Substrates were all sulphonated polystyrene-divinylbenzene strong

135 cation exchange resins (more specifications are given in Table S1).

\section{$136 \quad$ 2.2.2 $\quad$ Zr adsorption}

137 Resins were loaded with aqueous $\mathrm{ZrOCl}_{2}$ solutions using a batch contact time of one day and

138 mild agitation provided by a platform shaker (IKA, Germany). Macroporous resins were

139 loaded with volume-to-mass ratio (V/m) of $50 \mathrm{~mL} \mathrm{~g}^{-1}$ and $0.042 \mathrm{~mol} \mathrm{~L}^{-1} \mathrm{ZrOCl}_{2}$, while for

140 gel resins, $\mathrm{V} / \mathrm{m}$ of $1 \mathrm{~mL} \mathrm{~g}^{-1}$ and $2.8 \mathrm{~mol} \mathrm{~L}^{-1} \mathrm{ZrOCl}_{2}$ were used. Loaded resins were collected

141 under suction, washed with Milli- $\mathrm{Q}^{\circledR}$ water and leached for one day to remove un-adsorbed

142 Zr. The leached resins were re-rinsed, air-dried overnight under suction and vacuum-dried

143 overnight at $60{ }^{\circ} \mathrm{C}$ (Thermo Electron, Germany).

\section{$144 \quad 2.2 .3 \quad$ Thermal treatment}

145 Detailed conditions for carbothermal reduction were described in our previous work [7].

146 Briefly, the samples were heated in a graphite boat with lid in an alumina tube furnace under

147 a flow of $3.5 \mathrm{~mol} \% \mathrm{H}_{2}$ in Ar mix and 24 hour residence time at any specified temperature.

148 Heat treatment at $1350{ }^{\circ} \mathrm{C}$, being the maximum temperature achievable by the tube furnace,

149 was the standard procedure. Sample codes denote the $1350{ }^{\circ} \mathrm{C}$-heated materials, unless

150 explicitly stated otherwise.

\subsection{Characterisation}

152 Thermogravimetric analysis (TGA) of samples (vacuum-dried overnight at $100{ }^{\circ} \mathrm{C}$ ) was

153 conducted with a Seiko Instruments Inc. EXSTAR6000 thermal analyser under instrument air

154 carrier. Optical images were obtained with a Wild M400 optical macroscope. Secondary 
electron images of microsphere fractured surfaces (2-3 nm Pt coated) were acquired with a Zeiss Ultra Plus Scanning Electron Microscope (SEM). Scanning Transmission Electron Microscopy (STEM) images and Energy Dispersive Spectroscopy (EDS) spectra were acquired using a JEOL 2200FS operated at $200 \mathrm{keV}$. STEM specimens consisted of crushed grains mixed with ethanol and dispersed on holey carbon films supported on TEM Cu mesh grids. Nitrogen adsorption-desorption isotherms of samples (vacuum-degassed at $150{ }^{\circ} \mathrm{C}$ ) were acquired at $77 \mathrm{~K}\left(-196^{\circ} \mathrm{C}\right)$ on a Micromeritics ASAP 2020 instrument. Mercury intrusion profiles were obtained with a Micromeritics Autosorb IV 9520 Mercury Porosimeter. Total surface areas were calculated with the Brunauer-Emmett-Teller (BET) equation; micropore and external surface areas using a t-plot method; and pore size distributions with a Density Functional Theory (DFT), $\mathrm{N}_{2}$ on carbon slit pore model. Powder X-Ray Diffraction (XRD) patterns were acquired with a PANalytical X'pert Pro X-Ray Diffractometer using $\mathrm{Cu}$ weighted K $\alpha$ radiation 1.5406 / $1.5444 \AA$ A $2: 1$, a step size of 0.0334 ${ }^{\circ} 2 \theta$ and an effective scan step time of 624.965 s. Rietveld Analysis of $\mathrm{Zr}_{2} \mathrm{SC}$ was performed using Rietica software (Version 2.1), employing a Newton-Raphson refinement strategy.

170 Profile fitting was conducted with a pseudo-Voigt function, while backgrounds were fitted with a fifth order polynomial function. For Neutron Activation Analysis (NAA), neutron irradiation was conducted at the OPAL Research Reactor, Lucas Heights, Australia, in a thermal neutron flux of $2.2 \times 10^{13} \mathrm{~cm}^{-2} \mathrm{~s}^{-1}$ for five minutes. Gamma spectra were acquired using high purity Ge gamma detectors (P-type, 25\% relative efficiency). Standardisation was achieved using the $k_{0}$-method and certified gold wires standards [47]. Microanalysis of $\mathrm{O}$ content was performed using a routine inert gas fusion method and employing a LECO TCH600 instrument. All samples for NAA and O microanalysis were first vacuum-dried overnight at $100{ }^{\circ} \mathrm{C}$ and vials backfilled with $\mathrm{N}_{2}$. Raman spectra were collected using a Renishaw inVia Raman spectrometer equipped with a Peltier-cooled CCD detector and set up 
with either argon $(514 \mathrm{~nm})$ or $\mathrm{HeCd}(325 \mathrm{~nm})$ laser excitation. The carbon in-plane crystallite size was calculated using a general expression (Eq. 1) taking into account the laser wavelength:

$$
L_{a}=\left(2.4 \times 10^{-10}\right) \lambda_{\text {laser }}^{4}\left(\frac{I_{D}}{I_{G}}\right)^{-1}
$$

where $L_{a}$ is the in-plane crystallite size $(\mathrm{nm}), \lambda_{\text {laser }}$ is the laser wavelength $(\mathrm{nm}), I_{D}$ is the D peak intensity and $I_{G}$ is the G peak intensity [48]. Individual whole microspheres were mechanically tested between two metal flats (load cell and stationary surface) using an Instron 5967 instrument with $500 \mathrm{~N}$ load cell, employing a compression rate of $0.01 \mathrm{~mm}$ $187 \min ^{-1}$.

\subsection{Adsorption studies}

\subsubsection{Solution preparation}

190 For a pH 2 elemental selectivity profile, a $0.1 \mathrm{mg} \mathrm{L}^{-1}$ cocktail (with respect to each element)

191 was produced by diluting a multi-element custom standard 100-fold into $\mathrm{pH} 2.5$ nitric acid solution, with $\mathrm{pH}$ adjustment carried out by addition of aqueous $\mathrm{HNO}_{3}$, employing magnetic

193 stirring.

194 For $\mathrm{pH}$ dependence studies, a solution $10 \mathrm{mg} \mathrm{L}^{-1}$ with respect to Re was produced by

195 dissolution of $\mathrm{NaReO}_{4}$ in Milli- $\mathrm{Q}^{\circledR}$ water. With vigorous magnetic stirring, this was $\mathrm{pH}$

196 adjusted with aqueous $\mathrm{HNO}_{3}$ or $\mathrm{NaOH}$ solutions to produce subsamples of various $\mathrm{pH}$ values.

197 Each solution was aged for a day and its final $\mathrm{pH}$ measured.

198 For Re capacity measurements, STEM-EDS studies of Re loading and temperature

199 dependence, a $25 \mathrm{mg} \mathrm{L}^{-1}$ Re solution was produced by dissolution of $\mathrm{NaReO}_{4}$ in $\mathrm{Milli}-\mathrm{Q}^{\circledR}$ 
water, with adjustment to $\mathrm{pH} 5$ with dilute aqueous $\mathrm{HNO}_{3}$ and employing magnetic stirring.

201 Aged overnight, the $\mathrm{pH}$ change was negligible. For kinetics and reuse, $1 \mathrm{mg} \mathrm{L}^{-1}$ (pH 5) and

$20210 \mathrm{mg} \mathrm{L}^{-1}$ (pH 3) Re solutions, respectively, were prepared similarly.

\section{$203 \quad 2.4 .2$ Contact experiments}

204 Batch contact was conducted at about $20{ }^{\circ} \mathrm{C}$ with gentle agitation provided by a platform shaker (IKA, Germany), except for temperature dependence measurements, which were performed in a temperature-controlled shaker oven (WTC Binder, Germany).

207 The $\mathrm{pH} 2$ selectivity survey was performed in triplicate at volume-to-mass ratio $(\mathrm{V} / \mathrm{m})$ of 200

$208 \mathrm{~mL} \mathrm{~g}^{-1}$ with a contact time of one day. Supernatants were filtered through hydrophilic 0.45 $\mu \mathrm{m}$ syringe filters (Sartorius). Measurements of $\mathrm{pH}$ dependence were performed similarly, but with a contact time of three days.

211 For capacity measurements, single solid portions were contacted for four days, with $\mathrm{V} / \mathrm{m}$

212 varied between 50 and $1000 \mathrm{~mL} \mathrm{~g}^{-1}$. Subsampling of supernatants was conducted by pipette.

213 Re-loading of pre-ground STEM-EDS specimen was executed similarly, but with $V / m$ of

$2142000 \mathrm{~mL} \mathrm{~g}^{-1}$.

215 Kinetics measurements were performed in triplicate at $V / m$ of $200 \mathrm{~mL} \mathrm{~g}^{-1}$, with time varied

216 between 15 minutes and four days. Supernatants were subsampled by pipette.

217 For reuse studies, adsorption-desorption cycling was effected by changes in $\mathrm{HNO}_{3}$

218 concentration. A single solid portion was contacted with $10 \mathrm{mg} \mathrm{L}^{-1} \mathrm{Re}$ solution (pH 3) at V/m

219 of $200 \mathrm{~mL} \mathrm{~g}^{-1}$ for four days, with subsampling by pipette. The remaining supernatant was

220 removed and replaced with $\mathrm{HNO}_{3}$ solution $(\mathrm{pH} 0)$, with subsequent contact for four days,

221 followed by subsampling by pipette. This procedure was repeated for two full cycles. 
222 Between cycles, the solid material was washed and then leached $\left(V / m\right.$ of $\left.5000 \mathrm{~mL} \mathrm{~g}^{-1}\right)$ with 223 Milli-Q ${ }^{\circledR}$ water for three days, to remove residual $\mathrm{HNO}_{3}$.

224 Temperature dependence studies were carried out in triplicate with contact at $\mathrm{V} / \mathrm{m}$ of $200 \mathrm{~mL}$ $225 \mathrm{~g}^{-1}$ for four days, sequentially at 30,40 and $50{ }^{\circ} \mathrm{C}$, respectively. Supernatants were removed 226 by pipette and cooled to room temperature prior to dilution for ICP-MS analysis.

227 Elemental analyses of supernatants and stocks were performed on an Agilent 7900 ICP Mass

228 Spectrometer. Values of \% extraction were calculated using Eq. 2:

$$
\% \text { extraction }=\frac{C_{i}-C_{e}}{C_{i}} \times 100
$$

229 and uptakes were calculated with Eq. 3 and 4:

$$
\begin{gathered}
q_{e}=\frac{\left(C_{i}-C_{e}\right) V}{m} \\
q_{t}=\frac{\left(C_{i}-C_{t}\right) V}{m}
\end{gathered}
$$

230 where $C_{i}$ is initial concentration $\left(\mathrm{mg} \mathrm{L}^{-1}\right), C_{e}$ is equilibrium concentration $\left(\mathrm{mg} \mathrm{L}^{-1}\right), C_{t}$ is

231 concentration $\left(\mathrm{mg} \mathrm{L}^{-1}\right)$ at time $t, q_{e}$ is the equilibrium amount adsorbed $\left(\mathrm{mg} \mathrm{g}^{-1}\right), q_{t}$ is the

232 amount adsorbed $\left(\mathrm{mg} \mathrm{g}^{-1}\right)$ at time $t, V$ is volume (L) and $m$ is mass of sorbent $(\mathrm{g})$. Triplicates

233 were averaged and errors estimated from two sample standard deviations of each triplicate 234 set.

\section{$235 \quad$ 2.4.3 Model fitting and calculations}

236 Details of standard calculations for fitting adsorption models, as well as thermodynamic

237 calculations, are given in Supplementary Material. 
2393 Results and Discussion

\subsection{Loading of resins}

241 The Zr uptake of the various cation exchange resins exhibited considerable variation. While

242 the macroporous resins ( $\mathrm{ZrCX}-1$ and -2 precursors) were readily saturated with dilute $\mathrm{ZrOCl}_{2}$

243 solution ( $\left.0.042 \mathrm{~mol} \mathrm{~L}^{-1}\right)$ (Table S2), loading of the gel resins (ZrCX-3 to -5 precursors) was

244 only satisfactorily achieved with concentrated solutions $\left(2.8 \mathrm{~mol} \mathrm{~L}{ }^{-1}\right)$. From TGA of the

245 loaded resins (Fig. S1), the refractory residues (presumed to be $\mathrm{ZrO}_{2}$ ) were calculated to

246 verify successful loading with Zr. For ZrCX-1 to -5, these were 24.3, 25.0, 28.5, 10.6 and

$24710.4 \mathrm{wt} \%$, respectively.

\subsection{Effect of thermal treatment}

250 Carbothermal reduction products of the $\mathrm{Zr}$-loaded resins at $1350{ }^{\circ} \mathrm{C}$ were typically lustrous

251 black and highly spherical microspheres. A typical example, $\mathrm{ZrCX}-1$, is presented in Fig. 1

252 (images of all materials are supplied in Fig. S2). Upon heating, the specimens exhibited

253 noticeable shrinkage compared to the precursors. The measured BET surface areas for $\mathrm{ZrCX}$ -

2541 to -5 were $609,626,401,7.1$ and $7.5 \mathrm{~m}^{2} \mathrm{~g}^{-1}$, respectively. Thus, high $\mathrm{Zr}$ content seemed to

255 have a positive influence on surface area; the three loaded resins with much higher $\mathrm{Zr}$ content

256 (ZrCX-1 to -3$)$ gave very high BET surface areas. 


\subsection{Composition and chemical structure}

258 Elemental compositions of the thermally-treated microspheres were determined mainly using

259 NAA and supplemented with O microanalysis (Table 1). From NAA, the main constituents

260 were $\mathrm{Zr}$, S, Hf and $\mathrm{Na}$, with the remainder presumed to be mainly $\mathrm{C}$ and $\mathrm{O}$. Traces of $\mathrm{Cl}, \mathrm{Mg}$,

$261 \mathrm{Al}, \mathrm{V}, \mathrm{Mn}, \mathrm{Co}$ and Cs were also found (data not shown). The trends in measured $\mathrm{Zr}$

262 concentrations agreed well with those seen earlier in the TGA of unheated Zr-loaded resins.

263 The presence of Hf was anticipated as it is a common impurity in $\mathrm{Zr}$, due to the difficulty in

264 separating these two elements. The source of Na content was uncertain, however it could

265 indicate that the starting resins were prepared in their $\mathrm{Na}$ forms and converted to $\mathrm{H}$ forms

266 later on. Considerable O content (4.19-12.7\%) was also found. The O in the Zr-loaded

267 precursors originated from both sulphonate $\left(-\mathrm{SO}_{3} \mathrm{H}\right)$ and zirconyl $\left(\left[\mathrm{Zr}_{4}(\mathrm{OH})_{8}\right]^{8+}\right)$ moieties; the

268 naked polymer frameworks do not contain it. The compositional remainders (42-75.5 wt $\%$ ),

269 were inferred to be mainly $\mathrm{C}$, making up the porous frameworks and the majority component

270 in four out of the five materials.

271 Powder XRD patterns for ZrCX-1 to -5 are presented in Fig. 2a. Despite initial expectations

272 of producing $\mathrm{ZrC}$, the three high surface area materials, $\mathrm{ZrCX}-1$ to -3 , showed the same

273 distinct reflections of a crystalline phase identified as the MAX phase zirconium sulphide

274 carbide $\left(\mathrm{Zr}_{2} \mathrm{SC}\right)[29,30]$. The $\mathrm{Zr}_{2} \mathrm{SC}$ phase is known to have a $\mathrm{P} 6_{3} / m m c$ (hexagonal) space

275 group [30]. The other two materials displayed broad irregular shaped bumps which were

276 interpreted as amorphous content or very short-range order. Using Rietveld Analysis,

277 attempts were made at fitting a hexagonal structure model to the data. Fitting background

278 functions proved challenging due to the high background. Use of a beam knife did not

279 improve this situation (data not shown) and it was concluded that the backgrounds was due to

280 amorphous content. Despite this difficulty, peak positions were accurately fitted and lattice 
281 parameters calculated. The a and c cell dimensions ( $\AA$ ) for $\mathrm{Zr}_{2} \mathrm{SC}$ in $\mathrm{ZrCX}-1$ to -3 were, 282 respectively: $3.416 \pm 0.002,12.143 \pm 0.007 ; 3.417 \pm 0.004,12.150 \pm 0.014 ;$ and $3.423 \pm$ $2830.013,12.16 \pm 0.04$. These agreed well with previously reported values for this particular 284 MAX phase (summarised in Table S3) [49-57]. Interestingly, the Zr-to-S molar ratios 285 calculated from the compositional data above, ranged from 0.9 to 1.3 ; less than the $2: 1$ 286 proportions expected from the $\mathrm{Zr}_{2} \mathrm{SC}$ formula. The $\mathrm{Zr}$-to- $\mathrm{C}$ molar ratios ranged from about 2870.02 to 0.1 , indicating that $\mathrm{C}$ was in vast excess. However, given the close agreement in 288 lattice dimensions to prior examples, a deviation in stoichiometry of the MAX phase seems 289 unlikely.

290 The carbon phases of $\mathrm{ZrCX}-1$ to -3 were characterised by Raman Spectroscopy. Visible and

291 UV excitation Raman spectra for ZrCX-1 are shown (Fig. 2b); those of the other two

292 materials were highly similar and are given in Fig. S3. First, the absence of a discernible T 293 peak $\left(\sim 1060 \mathrm{~cm}^{-1}\right)$ in the $325 \mathrm{~nm}$ (UV excitation) spectrum demonstrated that $\mathrm{sp}^{3}$-hybridised 294 carbon content was insignificant. The $\mathrm{G}$ peak $\left(\sim 1600 \mathrm{~cm}^{-1}\right)$ was unambiguous evidence of a 295 ringed $\mathrm{sp}^{2}$ carbon structure. Furthermore, the $\mathrm{G}$ peak did not disperse (that is, change of peak 296 position as a function of laser excitation frequency), but only the D peak dispersed; this is 297 seen only in ordered carbons such as graphite, nanocrystalline graphite and glass-like carbon 298 [58]. Thus the carbon component of the composites appears to consist of a well-ordered 299 ringed $\mathrm{sp}^{2}$ carbon structure, with relatively few defects.

300 The 2D (overtone) peak provides information about stacking order of $\mathrm{sp}^{2}$ carbon sheets. In 301 highly-graphitised carbon, a fine structure is observed [48]. This was absent in the 2D peak of 302 the $514 \mathrm{~nm}$ spectrum of $\mathrm{ZrCX}-1$, which instead showed a single smooth symmetrical peak. 303 This was thus evidence of disordered stacking or turbostraticity of the carbon sheets similar 
to the so-called non-graphitic carbons [59]. An equally valid interpretation would be that the sheets were randomly positioned in space, relative to one other.

306 Summarising, while there was evidence of an ordered ringed $\mathrm{sp}^{2}$ graphene-like motif in

$307 \mathrm{ZrCX}-1$, the carbon matrix exhibited a disordered three-dimensional structure.

\subsection{Porosity}

309 The internal pore structures of the materials were investigated with SEM. In the two

310 macroporous resin-derived materials, $\mathrm{ZrCX}-1$ and -2 (Fig. 3a-d), no large macropores (i.e.

311 pores of the order of tens to hundreds of micrometres in diameter) could be observed. At

312 higher magnification, irregular coral-shaped polymer structures were observed in both

313 materials, surrounded by sub-micrometre macropores. Smaller gaps between adjacent

314 branches could be interpreted as mesopores. The gel resin-derived microspheres, ZrCX-3 to -

3155 (Fig. 3e-j), were also lacking in large macropores, but somewhat smoother surface textures

316 were observed at higher magnification. Thus, these latter materials did not have the small

317 meso- and macropore architectures of the macroporous resin-derived microspheres. While

318 some evident loose surface fragments were noted in two of the images, these were probably

319 artefacts of the sample preparation.

320 The high surface area materials $\mathrm{ZrCX}-1$ to -3 were examined by Nitrogen Porosimetry.

321 Adsorption-desorption isotherms of these materials are presented in Fig. 4a. All three Zr-

322 loaded resins developed considerable microporosity on heating, manifested as low relative

323 pressure branches characteristic of the Type I adsorption isotherm [60]. However, the

324 unloaded parent resins (Dowex ${ }^{\circledR}$ DR-2030, Amberlyst $^{\circledR} 15$ and Dowex ${ }^{\circledR}$ 50WX2,

325 respectively) upon similar heating, gave much lower surface areas of 25,59 and $<1 \mathrm{~m}^{2} \mathrm{~g}^{-1}$,

326 respectively. This implied that the inorganic portion played a role in the development of 
microporosity and also that volatilisation of carbonaceous material could be ruled out as a

cause. The two macroporous resin-derived materials retained considerable

mesoporous/macroporous character of their parents, in contrast to the gel resin, which

330 collapsed on heating to yield a non-porous product whose surface area was too low to

331 accurately measure.

332 While the gel resin-derived $\mathrm{ZrCX}-3$ exhibited a pure Type I isotherm, in $\mathrm{ZrCX}-1$ and $\mathrm{ZrCX}-2$

333 Type IV hysteresis loops were also observed, indicative of mesoporosity [60]. The hystereses

334 displayed reasonably flat plateaux, suggesting complete mesopore filling and the absence of

335 substantial macropore and/or external surface areas which would be manifested as Type II-

336 shaped features at relative pressures approaching unity [60]. The DFT pore size distributions

337 for $\mathrm{ZrCX}-1$ to -3 (Fig. 4b), confirmed a mixture of micro- and large mesopores for both

$338 \mathrm{ZrCX}-1$ and $\mathrm{ZrCX}-2$ and only micropores for $\mathrm{ZrCX}-3$. The former type of hierarchical

339 porosity would be highly desirable in order to facilitate mass transport.

340 Mercury Intrusion Porosimetry of whole microspheres was also undertaken (Fig. S4), but was

341 largely uninformative with respect to macropores. Apart from intrusion of interstitial

342 porosity, only mesopore openings were revealed; this thus demonstrated that the microsphere

343 surfaces were mesoporous.

\section{$344 \quad 3.5 \quad$ Mechanical testing}

345 Compressive strength testing of $\mathrm{ZrCX}-1$ to -5 microspheres was conducted. Material $\mathrm{ZrCX}-1$ was exceedingly robust with an average failure point of $38.3 \mathrm{~N}$ and sample standard deviation

347 of $6.3 \mathrm{~N}(\mathrm{n}=10)$. The microspheres shattered upon failure. A representative profile is given

348 in Fig. S5. The smaller-sized ZrCX-3 behaved similarly, with an average failure point of 24.7

$349 \mathrm{~N}$ and sample standard deviation of $4.8 \mathrm{~N}(\mathrm{n}=10)$. The two low surface area materials also 
proved to be mechanically strong and exhibited similar-shaped profiles, but also wideranging variation in mechanical strength. $\mathrm{ZrCX}-4$ yielded an average failure point of $26.0 \mathrm{~N}$ and sample standard deviation of $19.0 \mathrm{~N}(\mathrm{n}=12)$, while $\mathrm{ZrCX}-5$, the most robust of the series, gave an average failure point of $109.7 \mathrm{~N}$ and sample standard deviation of $62.3 \mathrm{~N}(\mathrm{n}=$ 10). However, the compression behaviour for material $\mathrm{ZrCX}-2(\mathrm{n}=11)$ was not reproducible with respect to profile shapes or failure points (data not shown), probably on account of the significant proportion of irregular-shaped microsphere fragments. Based on the brittle (albeit strong) overall nature of the materials and earlier presented Raman data, we would suggest that the carbon frameworks are probably akin to glass-like carbon.

Considering that a typical $\mathrm{ZrCX}-1$ microsphere weighed approximately $0.1 \mathrm{mg}$, it follows that the same could withstand a compressive force equivalent to approximately 40 million times its own weight (assuming $g$ of $9.81 \mathrm{~m} \mathrm{~s}^{-2}$ ). Therefore, mechanical strength should be no limitation for deployment in separation applications, such as in columns, batch contact or fluidised beds. In comparison, Drisko and co-workers produced fairly robust hierarchically porous zirconium titanium oxide beads which could withstand up to $0.57 \mathrm{~N}$ [61].

\subsection{Structural evolution with temperature}

366 Based on its combination of favourable properties including multi-scale porosity, high surface area and mechanical strength, $\mathrm{ZrCX}-1$ was selected for the further study of its structural evolution with temperature (Fig. 5). From XRD data, a crystalline phase identified as tetragonal $\mathrm{ZrO}_{2}\left(\mathrm{tZrO}_{2}\right)$ had formed by $450{ }^{\circ} \mathrm{C}$, which generally grew in intensity with

370 increasing temperature (Fig. S6a). By $1150{ }^{\circ} \mathrm{C}$, the peak intensity of $\mathrm{tZrO}_{2}$ had diminished somewhat and from around $1250{ }^{\circ} \mathrm{C}$, the hexagonal MAX phase $\mathrm{Zr}_{2} \mathrm{SC}$ appeared which had increased in intensity by $1350{ }^{\circ} \mathrm{C}$ (Fig 5a). 
373 Surface area changes were monitored from $350-1350^{\circ} \mathrm{C}$ (Fig. $5 \mathrm{~b}$; the complete set of 374 associated adsorption-desorption isotherms are given in Fig. S6b and c). The low external 375 surface areas for all temperatures confirmed that most of the BET surface area was associated 376 with micropore content. While it would be tempting to attribute microporosity to the

377 interstices between crystallites, or between crystallites and the carbon phase, the surface area 378 changes did not always correlate with the appearance or disappearance of the crystalline 379 phases. As examples, at $950{ }^{\circ} \mathrm{C}$ a large drop in surface area was seen even though no new 380 crystalline phase had appeared; and at the intermediate stage of $1150{ }^{\circ} \mathrm{C}$, surface area 381 increased dramatically despite the absence of a well-defined crystalline phase. Instead, we 382 postulate that surface area increases were due to the reaction of volatile oxygen with carbon 383 in situ and/or voids left in the carbon phase by reaction with the inorganic phases.

384 Conversely, surface area losses were due to consolidation of groups of smaller pores to form

385 larger ones. One might consider this a form of activation, although any O-containing 386 functionalities generated on the carbon surface would likely be removed by the reducing and 387 carburising conditions.

388 Calculation of carbon in-plane crystallite size, $L_{a}$, for $550-1350{ }^{\circ} \mathrm{C}$ (Fig. $5 \mathrm{c}$ ) revealed an 389 almost linear downward relationship with temperature. Intuitively, one might expect 390 carbonisation to give the opposite result, that is, coalescence of carbon domains, for example, 391 as displayed by polyacrylonitrile [62]. These observations, however, are consistent with 392 reactive carbon removal (postulated above) giving rise to increasingly tenuous connections 393 between carbon domains and statistically, the semblance of smaller average crystallite sizes.

394 Taken together, these characterisation data support a hypothesis of micropore generation 395 within the carbon phase. By extension, this explanation probably also accounts for the high 
surface areas of the other two MAX phase-containing materials; and the low surfaces of the two materials, $\mathrm{ZrCX}-4$ and -5 , in which the $\mathrm{Zr}_{2} \mathrm{SC}$ phase did not form.

\subsection{Adsorption properties}

The adsorption properties of $\mathrm{ZrCX}-1$ were scoped for a large suite of 41 elements at $\mathrm{pH} 2$ (please refer to $§ 2.1$ Materials for the full list). The material showed significant extraction only of oxospecies-forming elements, As $(94 \pm 4 \%)$, Se $(93 \pm 4 \%), \operatorname{Re}(87 \pm 7 \%)$ and $\mathrm{P}(>$ 95\%), with no discernible cation adsorption. Both Se and Re exist under these conditions of $\mathrm{pH}$ and concentration as oxoanions, although interestingly, $\mathrm{As}(\mathrm{V})$ and $\mathrm{P}(\mathrm{V})$ are found predominantly as the neutral species, arsenic acid $\left(\mathrm{H}_{3} \mathrm{AsO}_{4}\right)$ and phosphoric acid $\left(\mathrm{H}_{3} \mathrm{PO}_{4}\right)$ $[63,64]$.

The adsorption of Re prompted us to consider ${ }^{99} \mathrm{Tc}$ as a credible adsorbate, given the close similarity in chemistry between these two elements. Existing as the mononuclear tetrahedral anionic species, perrhenate $\left(\mathrm{ReO}_{4}^{-}\right)$, $\mathrm{Re}$ is analogous to its cousin in Group 7, one period above, Tc, which exists as pertechnetate $\left(\mathrm{TcO}_{4}^{-}\right)$[64]. Thus, it is often regarded as a surrogate to predict likely affinity for Tc. The adsorption of $\mathrm{ReO}_{4}{ }^{-}$as a function of $\mathrm{pH}$ was further investigated for both $\mathrm{ZrCX}-1$ as well as a carbon blank produced by heat-treating the Dowex ${ }^{\circledR}$ DR-2030 parent resin in the same way (S.A.BET $=25 \mathrm{~m}^{2} \mathrm{~g}^{-1}$ ) (Fig. 6a). Material $\mathrm{ZrCX}-1$ showed nearly quantitative extraction of $\mathrm{ReO}_{4}{ }^{-}$over the range of $\mathrm{pH} 3-10.5$. By way of comparison, the carbon blank only showed weak affinity, with discernible adsorption only over the range of $\mathrm{pH} 1-5$ and a maximum extraction of $c a .20 \%$ at $\mathrm{pH} 3$. The adsorption capacity of $\mathrm{ZrCX}-1$ for $\mathrm{ReO}_{4}^{-}$at pH 5 was also assessed (Fig. 6b). Isotherm model parameters obtained from fitting to the experimental data are presented in Table 2 . The 
419 Freundlich model was a poor fit, with significant non-linearity evident in the data. The

420 Langmuir model fit, however, was considerably better. The calculated value of $q_{\max }$

421 (adsorption capacity) for the latter model was a modest $13.85 \mathrm{mg} \mathrm{g}^{-1}\left(\mathrm{ca} .0 .074 \mathrm{mmol} \mathrm{g}^{-1}\right)$,

422 which visually accorded well with the plotted isotherm data. Capacity of the carbon blank

423 was also surveyed at $\mathrm{pH} 5$ for comparison and showed no measurable adsorption, in

424 agreement with the $\mathrm{pH}$ dependence discussed above. Since the high carbon micropore surface

425 area of $\mathrm{ZrCX}-1$ was obviously underutilised, one avenue for increasing adsorption capacity

426 could be to activate this carbon surface by sulphonation; load additional Zr; and repeat

427 carbothermal reduction treatment.

428 The Re adsorption kinetics of $\mathrm{ZrCX}-1$ were investigated (Fig. 6c). Fit parameters for the 429 pseudo-second-order model are presented in Table 3. Overall, the pseudo-second-order model

430 proved to be reasonable fit to the data. The kinetics were found to be be relatively slow, with

431 equilibrium only reached in 48-72 hours. Measured uptake at 24 hours was $c a .96 \%$ of $q_{\mathrm{e}}$.

432 These results can probably be attributed to a lack of large macropores which would facilitate

433 fast intraparticle diffusion.

434 Measurements of temperature dependence of $\mathrm{Re}$ adsorption onto $\mathrm{ZrCX}-1$ were undertaken to 435 quantify the associated thermodynamic parameters (Table 4). Increasing temperature had the 436 effect of reducing the $K_{\mathrm{d}}$ value (Fig. S8). Large negative values of $\Delta H^{\circ}$ (enthalpy) and $\Delta G^{\circ}$

437 (Gibbs free energy) were calculated, clearly implying that the adsorption was an exothermic 438 and spontaneous process. The negative value of $\Delta S^{\circ}$ (entropy) would indicate ordering at the 439 solid surface.

440 One might find the preceding fairly convincing evidence for the $\mathrm{Zr}_{2} \mathrm{SC}$ phase supplying the 441 majority of adsorption sites. However, efforts were made to corroborate this directly by way 442 of microstructural chemical analysis. Elemental mapping of a portion of the Re-loaded $\mathrm{ZrCX}$ - 
4431 material was undertaken using STEM-EDS (Fig. 7). The bright field image of ZrCX-1 (Fig.

444 6a) exhibited dark inorganic particles suspended on the lighter-shaded carbon phase.

445 Mapping of $\mathrm{Zr}, \mathrm{S}, \mathrm{O}$ and Re elemental distributions (Fig. 7b-e, respectively) demonstrated 446 that these four elements were mainly associated with one another. Thus, this unequivocally

447 demonstrated that $\mathrm{ReO}_{4}{ }^{-}$accumulates upon the $\mathrm{Zr}_{2} \mathrm{SC}$ aggregates/particles, with no

448 significant adsorption on the carbon phase. With reference to the earlier bulk compositional 449 data, these results also suggest that $\mathrm{O}$ and excess $\mathrm{S}$ are not associated with the carbon phase; 450 and in addition to the $\mathrm{Zr}_{2} \mathrm{SC}$ itself, may be part of a secondary inorganic phase. Due to the 451 very small scale of the STEM specimen, however, it cannot be ruled out that there are 452 pockets of unreacted material within the bulk of the material, rendered inaccessible to the 453 carbothermal treatment by shrinkage of the resin precursor during heating. It is also possible that some $\mathrm{O}$ is dissolved within the $\mathrm{Zr}_{2} \mathrm{SC}$ lattice. This latter explanation is plausible, given that other studies have shown that very high temperatures are required to completely remove dissolved $\mathrm{O}$ from $\mathrm{ZrC}$ and $\mathrm{HfC}$ powders [65].

457 The adsorption results presented above, certainly do contrast with most previous studies of 458 MXenes, which typically show cation extraction; adsorption of alkali metals, alkaline earth metals, $\mathrm{Pb}$ as well as $\mathrm{U}$, have all been demonstrated [66-68]. It should be noted, however, that

460 Ying and co-workers reported affinity of $\mathrm{Ti}_{3} \mathrm{C}_{2} \mathrm{~T}_{\mathrm{x}}(\mathrm{T}=\mathrm{OH}$ or $\mathrm{F})$ for $\mathrm{Cr}_{2} \mathrm{O}_{7}^{2-}$, seemingly

461 attributable to protonated surface hydroxyl groups [69]. We postulate two mechanisms for Re 462 adsorption, which are not necessarily mutually exclusive. The first is a surface electrostatic 463 model involving attraction by regions of negative charge on high-electronegative $\mathrm{O}$ bound to the adsorbate, to regions of positive charge on the carbide surface. This is a strong hypothesis, as it should universally explain adsorption of neutral, anionic and cationic oxospecies. We have also, in fact, observed the adsorption of cationic $\mathrm{UO}_{2}{ }^{2+}$ above $\mathrm{pH} 3$, as well as neutral and anionic Mo species $\left(\mathrm{H}_{2} \mathrm{MoO}_{4}, \mathrm{HMoO}_{4}{ }^{-}\right.$and $\left.\mathrm{MoO}_{4}{ }^{2-}\right)$ (Fig. S7). In a 
second scenario, it is conceivable that the "A layer" S terminating at the solid-liquid interface is oxidised and anion-exchangeable by adsorbate molecules. If this second hypothesis is applicable to any degree, one should expect a concomitant release of $\mathrm{S}$ into the surrounded solution.

472 There have been relatively few studies on the neutron irradiation stability of MAX phases 473 [70-77]. Some phases such as the well-studied $\mathrm{Ti}_{3} \mathrm{SiC}_{2}$ and $\mathrm{Ti}_{3} \mathrm{AlC}_{2}$ appear to be reasonably tolerant and may be candidate nuclear structural materials. There would seem to be evidence supporting the role of the A layer in accommodating antisite defects, thus aiding in damage recovery over amorphisation $[71,77]$. The antisite formation energies are in turn, influenced by the bonding overlap in the MX layer [71, 73]. The specific performance of $\mathrm{Zr}_{2} \mathrm{SC}$ in these respects is unknown. A further consideration is that the cited studies focus on changes to mechanical properties; as to what influence structural damage (if any) might have on the surface chemistry and observed adsorption properties is a question that remains to be answered. Nonetheless, these previous investigations do hold some promise for the durability of the $\mathrm{ZrCX}-1$ sorbent, subjected to irradiation.

The reusability of $\mathrm{ZrCX}-1$ was studied two complete adsorption-desorption cycles by varying the $\mathrm{HNO}_{3}$ concentration of the contact solution. For cycle one, $96 \%$ adsorption was observed and $76 \%$ desorption; for cycle $2,96 \%$ adsorption and $89 \%$ desorption. These preliminary results show that the $\mathrm{ReO}_{4}{ }^{-}$adsorption is in principle reversible, although additional work will be needed to establish optimal conditions. 


\section{Conclusions}

490 The synthesis of new mechanically robust and highly porous microsphere composites of

491 carbon and the hexagonal MAX phase $\mathrm{Zr}_{2} \mathrm{SC}$, based on a non-laborious procedure involving

492 the carbothermal reduction of Zr-loaded common strong cation exchange resins has been

493 demonstrated. The $\mathrm{Zr}$ loadings achieved varied among the resins and appeared to be an

494 important factor in the development of high surface areas and formation of $\mathrm{Zr}_{2} \mathrm{SC}$, which

495 were observed in one gel resin-derived and both macroporous resin-derived materials. Cell

496 dimensions of this phase determined by Rietveld Method agreed well with prior published

497 examples. It was concluded based on Raman data that the carbon phase consisted of ordered

498 carbon sheets with disordered stacking or random orientation in space. Porosity was

499 investigated in the three high surface area $\mathrm{Zr}_{2} \mathrm{SC}$-containing materials using SEM and

500 Nitrogen Porosimetry. All had developed microporosity, while the two macroporous-resin

501 derived materials additionally contained mesopores and small macropores originating from

502 their substrate resins.

503 Of the three $\mathrm{Zr}_{2} \mathrm{SC}$-containing materials, $\mathrm{ZrCX}-1$ was chosen for further study based on its

504 combination of favourable properties including high surface area, mechanical strength and multi-scale porosity. For $\mathrm{ZrCX}-1$, trends in crystallisation, surface area and carbon in-plane crystallite size as a function of temperature, together supported a hypothesis of micropore

507 formation occurring within the carbon phase due to reactive carbon removal. This carbon

508 phase is ostensibly a relative of glass-like carbon. This hypothesied mechanism probably also

509 accounts for the high surface areas of the other two MAX-phase materials in the series.

510 Investigation of $\mathrm{ZrCX}-1$ for adsorption selectivity at $\mathrm{pH} 2$, showed affinity for oxospecies-

511 forming elements, including As, Se, Re and P. Both neutral and anionic species were shown

512 to adsorb, suggesting that an electrostatic interaction must play at least some role. Re was 
513 then used as a surrogate in studies designed to anticipate the performance in extraction of

$514{ }^{99} \mathrm{Tc}$, a long-lived fission product in High Level Waste (HLW). Nearly quantitative extraction

515 over the range of $\mathrm{pH} 3-10.5$ was demonstrated, with over $90 \%$ extraction observed from $\mathrm{pH}$

516 2. Elemental mapping employing TEM-EDS confirmed the role of the $\mathrm{Zr}_{2} \mathrm{SC}$ MAX phase in

517 the adsorption of $\mathrm{ReO}_{4}^{-}$. The Langmuir model provided a superior fit to adsorption isotherm

518 data at $\mathrm{pH} 5$, yielding a $q_{\max }$ constant (Langmuir adsorption capacity) of $13.85 \mathrm{mg} \mathrm{g}^{-1}$. A

519 suggestion for further optimising this characteristic was offered. Likewise, adsorption

520 kinetics for $\mathrm{ZrCX}-1$ were modelled by pseudo-second-order model and found to be relatively

521 slow (equilibrium reached in 48-72 hours), suggesting future opportunities for optimisation

522 of pore architecture. Thermodynamic measurements demonstrated that the adsorption process

523 was spontaneous and exothermic. The adsorption was also shown to be reversible, indicating

524 the possibility for recycling of the matrix.

525 Given the simplicity of their syntheses and porous granular natures affording potential use in

526 a chromatographic column, one might envisage one application being the deployment of the

527 materials for the direct selective extraction of ${ }^{99} \mathrm{Tc}$ from HLW and subsequent transmutation

528 with thermal neutrons. For instance, the microspheres could be packed into a column within a

$529 \mathrm{Zr}$-alloyed housing, for convenient loading of ${ }^{99} \mathrm{Tc}$, neutron irradiation and post-irradiation

530 elution of products. The microspheres are rigid and not subject to swelling effects, unlike

531 polymeric ion exchange resins and are not likely to be damaged by fission gas build-up.

532 Although radiation tolerance is anticipated, this will need to be evaluated for the $\mathrm{Zr}_{2} \mathrm{SC}$ phase

533 to properly gauge practical lifespan in a real recycling scenario. That is to say, while prior

534 radiation damage studies of other MAX phases indicate good general stability for this class of

535 materials, the specific performance of the $\mathrm{Zr}_{2} \mathrm{SC}$ MAX phase in high thermal neutron fluxes

536 would need to be addressed if it is to be considered for this application. This is a question we

537 are working towards answering. 


\section{Acknowledgements}

540 Materials and equipment access were provided and/or funded by Australian Nuclear Science

541 and Technology Organisation (ANSTO). The authors thank the following ANSTO staff for

542 their contributions: Mr Kerry Cruikshank and Dr Ken Short for maintenance and repair of our

543 tube furnace; Mr Karl Toppler and Mr Tim Nicholls for assistance with mechanical testing

544 equipment; Mr Joel Davis for SEM data; and Dr Yingjie Zhang for Chinese language

545 translations. Mercury Porosimetry was conducted by Particle \& Surface Sciences Pty Ltd,

546 NSW, Australia, and O microanalysis was performed by CSIRO Mineral Resources, VIC,

547 Australia; both on a pay-per-sample basis. N.S. is grateful to Dr Katerina Bendak of the

548 Children's Cancer Institute, Kensington, Australia, for German language translations. This

549 research has been conducted with the support of the Australian Government Research

550 Training Program Scholarship. Professor Chen also acknowledges the continuous support

551 from Australian National Fabrication Facility (ANFF).

552

553 Figures captions

Fig. 1. Optical microscopy image of $\mathrm{ZrCX}-1$.

556 Fig. 2. (a) Powder XRD patterns. Key: h, hexagonal $\mathrm{Zr}_{2} \mathrm{SC}$; and (b) Raman spectra of ZrCX-

557 1, representative of $\mathrm{ZrCX}-1$ to -3. 
558 Fig. 3. SEM images of internal fractured microsphere surfaces at 1,000 and 50,000 $\times$

559 magnification. (a) and (b) ZrCX-1; (c) and (d) ZrCX-2; (e) and (f) $\mathrm{ZrCX}-3$; (g) and (h) $\mathrm{ZrCX}$ -

$560 \quad 4$; and (i) and (j) ZrCX-5.

561 Fig. 4. Nitrogen Porosimetry data. (a) adsorption-desorption isotherms; and (b) pore size

562 distributions.

563 Fig. 5. Structural evolution of ZrCX-1 with temperature. (a) Powder XRD patterns. Key: t,

564 tetragonal $\mathrm{ZrO}_{2}$; h, hexagonal $\mathrm{Zr}_{2} \mathrm{SC}$; (b) micropore, external and BET surface areas; and (c)

565 in-plane carbon crystallite sizes.

566 Fig. 6. Adsorption data. (a) $\mathrm{pH}$ dependence for $\mathrm{ReO}_{4}{ }^{-}$adsorption onto $\mathrm{ZrCX}-1$ and a carbon

567 blank; (b) isotherm data for $\mathrm{ReO}_{4}{ }^{-}$adsorption onto $\mathrm{ZrCX}-1$ at $\mathrm{pH} 5$ with fitted Langmuir and

568 Freundlich models; and (c) kinetics data for $\mathrm{ReO}_{4}{ }^{-}$adsorption onto $\mathrm{ZrCX}-1$ at $\mathrm{pH} 5$ with

569 pseudo-second-order model fit.

570 Fig. 7. STEM studies of Re-loaded ZrCX-1. (a) Bright field image; and corresponding

571 STEM-EDS elemental maps (b-e) of Zr, S, O and Re distributions.

572

573 Tables

574 Table 1. Elemental compositions of $\mathrm{ZrCX}-1$ to -5.

\begin{tabular}{lcccccc}
\hline Material & $\mathrm{Zr}(w t \%)$ & $S(w t \%)$ & $O(w t \%)$ & $H f(w t \%)$ & $N a(w t \%)$ & Balance (wt\%) \\
\hline ZrCX-1 & $26 \pm 2$ & $6.9 \pm 0.5$ & $9.9 \pm 0.2$ & $0.58 \pm 0.04$ & $0.0043 \pm 0.0003$ & $57 \pm 2$ \\
ZrCX-2 & $26 \pm 2$ & $8.0 \pm 0.6$ & $10.2 \pm 0.2$ & $0.57 \pm 0.04$ & $0.0051 \pm 0.0004$ & $55 \pm 2$ \\
& & & & & & \\
ZrCX-3 & $32 \pm 2$ & $12.2 \pm 0.9$ & $12.7 \pm 0.3$ & $0.75 \pm 0.05$ & $0.0179 \pm 0.0013$ & \\
& & & & & & \\
\end{tabular}




$\begin{array}{lcccccc}\text { ZrCX-4 } & 11.4 \pm 0.8 & 8.6 \pm 0.7 & 4.19 \pm 0.08 & 0.27 \pm 0.02 & 0.060 \pm 0.004 & 75.5 \pm 1.5 \\ & & & & & \\ \text { ZrCX-5 } & 12.3 \pm 0.9 & 9.6 \pm 0.8 & 4.48 \pm 0.09 & 0.29 \pm 0.02 & 0.40 \pm 0.03 & 73.0 \pm 1.7\end{array}$

575

576

577 Table 2. Isotherm model fit parameters for $\mathrm{ReO}_{4}{ }^{-}$adsorption onto $\mathrm{ZrCX}-1$ at $\mathrm{pH} 5$.

\begin{tabular}{cccccc}
\hline Model & $q_{\max }\left(\mathrm{mg} \mathrm{g}^{-1}\right)$ & $b\left(\mathrm{~L} \mathrm{mg}^{-1}\right)$ & $n$ & $K_{f}\left(m g g^{-1}\right)$ & $R^{2}$ \\
\hline Langmuir & 13.85 & 1.59 & & & 0.993 \\
Freundlich & & 2.97 & 6.56 & 0.949 \\
& & & & \\
\hline
\end{tabular}

578

579

580

581 Table 3. Kinetic model fit parameters for $\mathrm{ReO}_{4}{ }^{-}$adsorption onto $\mathrm{ZrCX}-1$ at pH 5.

\begin{tabular}{cccc}
\hline Model & $q_{e}\left(m g g^{-1}\right)$ & $k_{2}\left(g m g^{-1} h^{-1}\right)$ & $R^{2}$ \\
\hline Pseudo-second-order & 0.200 & 2.36 & 0.999 \\
\hline
\end{tabular}

582

583

584 Table 4. Thermodynamic parameters for $\mathrm{ReO}_{4}{ }^{-}$adsorption onto $\mathrm{ZrCX}-1$ at pH 5 .

\begin{tabular}{cccc}
\hline$\Delta S^{\circ}\left(\mathrm{J} \mathrm{K}^{-1} \mathrm{~mol}^{-1}\right)$ & $\Delta H^{\circ}\left(\mathrm{kJ} \mathrm{mol}^{-1}\right)$ & Temperature $\left({ }^{\circ} \mathrm{C}\right)$ & $\Delta G^{\circ}\left(\mathrm{kJ} \mathrm{mol}^{-1}\right)$ \\
& & & \\
\hline-109.0 & -57.07 & 30 & -24.01
\end{tabular}




\section{References}

590 [1] K. Kora, H. Nakaya, H. Matsuura, M. Goto, S. Nakagawa, S. Shimakawa, A study on 591 transmutation of LLFPs using various types of HTGRs, Nucl. Eng. Des., 300 (2016) 330-338. 592 [2] B.R. Bergelson, A.S. Gerasimov, G.V. Tikhomirov, Radiotoxicity and decay heat power 593 of spent nuclear fuel of VVER type reactors at long-term storage, Radiat Prot Dosimetry, 115 594 (2005) 445-447.

595 [3] A Technology Roadmap for Generation IV Nuclear Energy Systems, 2002.

596 [4] S. Pillon, Actinide-bearing fuels and transmutation targets, in: R.J.M. Konings (Ed.)

597 Comprehensive Nuclear Materials, Elsevier B.V., 2012, pp. 109-141.

598 [5] J. Lamontagne, Y. Pontillon, E. Esbelin, S. Bejaoui, B. Pasquet, P. Bourdot, J.M.

599 Bonnerot, Determining the americium transmutation rate and fission rate by post-irradiation 600 examination within the scope of the ECRIX-H experiment, J. Nucl. Mater., 440 (2013) 366601376.

602 [6] M. Salvatores, I. Slessarev, A. Tchistiakov, The transmutation of long-lived fission 603 products by neutron irradiation, Nucl. Sci. Eng., 130 (1998) 309-319.

604 [7] N. Scales, J. Chen, T.L. Hanley, D.P. Riley, G.R. Lumpkin, V. Luca, Hierarchically 605 porous carbon-zirconium carbide spheres as potentially reusable transmutation targets, 606 Microporous Mesoporous Mater., 212 (2015) 100-109.

607 [8] Y. Katoh, G. Vasudevamurthy, T. Nozawa, L.L. Snead, Properties of zirconium carbide 608 for nuclear fuel applications, J. Nucl. Mater., 441 (2013) 718-742.

609 [9] B. Gu, K.E. Dowlen, L. Liang, J.L. Clausen, Efficient separation and recovery of 610 technetium-99 from contaminated groundwater, Sep. Technol., 6 (1996) 123-132.

611 [10] E. Holm, T. Gafvert, P. Lindahl, P. Roos, In situ sorption of technetium using activated 612 carbon, Appl. Radiat. Isot., 53 (2000) 153-157.

613 [11] Y.F. Wang, H.Z. Gao, R. Yeredla, H.F. Xu, M. Abrecht, Control of pertechnetate 614 sorption on activated carbon by surface functional groups, Journal of Colloid and Interface 615 Science, 305 (2007) 209-217. 
616 [12] N.N. Popova, G.L. Bykov, G.A. Petukhova, I.G. Tananaev, B.G. Ershov, Sorption of

617 Tc(VII) and Am(III) by carbon materials: effect of oxidation, J. Radioanal. Nucl. Chem., 298

$618 \quad$ (2013) 1463-1468.

619 [13] H. Zhuang, J. Zeng, L. Zhu, Sorption of radionuclides technetium and iodine on

620 minerals, Radiochim. Acta, 44-45 (1988) 143-145.

621 [14] A. Winkler, H. Bruehl, C. Trapp, W.D. Bock, Mobility of technetium in various rocks

622 and defined combinations of natural minerals, Radiochim. Acta, 44-45 (1988) 183-186.

623 [15] S. El-Wear, K.E. German, V.F. Peretrukhin, Sorption of technetium on inorganic

624 sorbents and natural minerals, J. Radioanal. Nucl. Chem., 157 (1992) 3-14.

625 [16] L. Liang, B. Gu, X. Yin, Removal of technetium-99 from contaminated groundwater

626 with sorbents and reductive materials, Sep. Technol., 6 (1996) 111-122.

627 [17] M.J. Kang, S.W. Rhee, H. Moon, V. Neck, T. Fanghaenel, Sorption of MO4- (M = Tc,

$628 \mathrm{Re}$ ) on Mg/Al layered double hydroxide by anion exchange, Radiochim. Acta, 75 (1996) 169-

629173.

630 [18] D.J. Liu, X.H. Fan, Adsorption behavior of 99Tc on Fe, Fe2O3 and Fe2O4, J. Radioanal.

631 Nucl. Chem., 264 (2005) 691-698.

632 [19] V. Peretroukhine, C. Sergeant, G. Deves, S. Poulain, M.H. Vesvres, B. Thomas, M.

633 Simonoff, Technetium sorption by stibnite from natural water, Radiochim. Acta, 94 (2006)

634 665-669.

635 [20] R. Koivula, R. Harjula, Selective sorption of technetium on antimony-doped tin dioxide,

636 Sep. Sci. Technol., 46 (2011) 315-320.

637 [21] G. Sheng, Y. Tang, W. Linghu, L. Wang, J. Li, H. Li, X. Wang, Y. Huang, Enhanced

638 immobilization of ReO4- by nanoscale zerovalent iron supported on layered double

639 hydroxide via an advanced XAFS approach: Implications for TcO4- sequestration, Appl.

640 Catal., B, 192 (2016) 268-276.

641 [22] I.E. Burgeson, J.R. Deschane, D.L. Blanchard, Jr., Removal of technetium from Hanford

642 tank waste supernates, Sep. Sci. Technol., 40 (2005) 201-223.

643 [23] H. Fei, D.L. Rogow, S.R.J. Oliver, Reversible Anion Exchange and Catalytic Properties

644 of Two Cationic Metal-Organic Frameworks Based on $\mathrm{Cu}(\mathrm{I})$ and $\mathrm{Ag}(\mathrm{I}), \mathrm{J}$. Am. Chem. Soc.,

645132 (2010) 7202-7209.

646 [24] R. Cao, B.D. McCarthy, S.J. Lippard, Immobilization, Trapping, and Anion Exchange of

647 Perrhenate Ion Using Copper-Based Tripodal Complexes, Inorg. Chem., 50 (2011) 9499-

6489507.

649 [25] D. Sheng, L. Zhu, C. Xu, C. Xiao, Y. Wang, Y. Wang, L. Chen, J. Diwu, J. Chen, Z.

650 Chai, T.E. Albrecht-Schmitt, S. Wang, Efficient and Selective Uptake of TcO4- by a Cationic

651 Metal-Organic Framework Material with Open Ag+ Sites, Environ. Sci. Technol., 51 (2017)

652 3471-3479.

653 [26] L. Zhu, C. Xiao, X. Dai, J. Li, D. Gui, D. Sheng, L. Chen, R. Zhou, Z. Chai, T.E.

654 Albrecht-Schmitt, S. Wang, Exceptional Perrhenate/Pertechnetate Uptake and Subsequent

655 Immobilization by a Low-Dimensional Cationic Coordination Polymer: Overcoming the

656 Hofmeister Bias Selectivity, Environ. Sci. Technol. Lett., 4 (2017) 316-322.

657 [27] D. Banerjee, W. Xu, Z. Nie, L.E.V. Johnson, C. Coghlan, M.L. Sushko, D. Kim, M.J.

658 Schweiger, A.A. Kruger, C.J. Doonan, P.K. Thallapally, Zirconium-Based Metal-Organic

659 Framework for Removal of Perrhenate from Water, Inorg. Chem., 55 (2016) 8241-8243.

660 [28] X. Shu, L. Shen, Y. Wei, D. Hua, Synthesis of surface ion-imprinted magnetic

661 microsphere for efficient sorption of perrhenate: A structural surrogate for pertechnetate, J.

662 Mol. Liq., 211 (2015) 621-627.

663 [29] H. Nowotny, W. Jeitschko, F. Benesovsky, Novel complex carbides and nitrides and

664 their relation to phases of hard substances, Planseeber. Pulvermetall., 12 (1964) 31-43. 
[30] M.W. Barsoum, The MN+1AXN phases: a new class of solids; thermodynamically stable nanolaminates, Prog. Solid State Chem., 28 (2000) 201-281. [31] M. Naguib, M. Kurtoglu, V. Presser, J. Lu, J. Niu, M. Heon, L. Hultman, Y. Gogotsi, M.W. Barsoum, Two-Dimensional Nanocrystals Produced by Exfoliation of Ti3AlC2, Adv. Mater. (Weinheim, Ger.), 23 (2011) 4248-4253.

670 [33] K.F. Blurton, Preparation of highly dispersed platinum on carbon, Carbon, 10 (1972) 305-315. [34] K. Miura, H. Nakagawa, Preparation of metal-loaded porous carbons and their use as a highly active catalyst for reduction of nitric oxide (NO), in: E. Yasuda, M. Inagaki, K. Kaneko, M. Endo, A. Oya, Y. Tanabe (Eds.) Carbon Alloys: Novel Concepts to Develop Carbon Science and Technology, Elsevier Science Ltd., 2003, pp. 499-513. [35] P. Trens, V. Caps, J.W. Peckett, Catalytic oxidation of trans-stilbene using pyrolysed manganese-loaded cation exchange resin, Appl. Catal., A, 251 (2003) 19-28. [36] P. Trens, J.W. Peckett, V.N. Stathopoulos, M.J. Hudson, P.J. Pomonis, Phosphotungstate anions supported on spherical beads of carbon as highly efficient catalysts for the dehydration of propan-2-ol to propene, Appl. Catal., A, 241 (2003) 217-226.

683 [37] B. Li, Y. Ren, Q. Fan, A. Feng, W. Dong, Preparation and characterization of spherical 684 nickel-doped carbonaceous resin as hydrogenation catalysts. I. Carbonization procedures, 685 Carbon, 42 (2004) 2669-2676.

686 [38] W. Yu, J. Zheng, X. He, Y. Zhao, Synthesis of spherical activated carbon loaded with metal particles and its performance of thiophene adsorption, Huagong Xuebao (Chin. Ed.), 59 (2008) 2824-2829.

[39] W. Yu, Y. Zhang, T. Li, Y. Zhao, X. Qu, Y. Liu, S. Li, Spherical activated carbon material loaded with metal, and preparation method and application thereof, CN101385966A, 2009.

[40] S. Kudo, T. Maki, K. Miura, K. Mae, High porous carbon with $\mathrm{Cu} / \mathrm{ZnO}$ nanoparticles made by the pyrolysis of carbon material as a catalyst for steam reforming of methanol and dimethyl ether, Carbon, 48 (2010) 1186-1195.

[41] M.S. Wilson, A. Delariva, F.H. Garzon, Synthesis of sub-2 nm ceria crystallites in carbon matrixes by simple pyrolysis of ion-exchange resins, J. Mater. Chem., 21 (2011) 7418-7424.

[42] L. Kotai, T. Pasinszki, Z. Czegeny, S. Balint, I. Sajo, Z. May, P. Nemeth, Z. Karoly, P.K. Sharma, V. Sharma, K.K. Banerji, Metal and metal-sulfide containing carbons from sulfonated styrene-divinylbenzene copolymer based ion-exchangers, Eur. Chem. Bull., 1 (2012) 398-400.

[43] W. Li, Z. Zhang, A. Cui, J. Fan, X. Sun, A gasoline desulfurization adsorbent and preparation method thereof, CN103143321A, 2013.

[44] J. Fan, H. Lan, Z. Zhang, W. Li, Study on gasoline adsorptive desulfurization of resinbased modified spherical activated carbon, Shiyou Lianzhi Yu Huagong, 45 (2014) 10-15. [45] R.L. Beatty, Microspheres containing metal carbide from metal-charged resin beads, DE2527093A1, 1976.

[46] L. Tosheva, J. Parmentier, S. Saadallah, C. Vix-Guterl, V. Valtchev, J. Patarin, Carbon and SiC Macroscopic Beads from Ion-Exchange Resin Templates, J. Am. Chem. Soc., 126 (2004) 13624-13625.

[47] A. Simonits, F. De Corte, J. Hoste, Single-comparator methods in reactor neutron activation analysis, J. Radioanal. Chem., 24 (1975) 31-46. 
713 [48] M.A. Pimenta, G. Dresselhaus, M.S. Dresselhaus, L.G. Cancado, A. Jorio, R. Saito,

714 Studying disorder in graphite-based systems by Raman spectroscopy, Phys. Chem. Chem.

715 Phys., 9 (2007) 1276-1291.

716 [49] H. Kudielka, H. Rohde, Structural investigations of carbosulfides of titanium and

717 zirconium, Z. Kristallogr., Kristallgeom., Kristallphys., Kristallchem., 114 (1960) 447-456.

718 [50] A. Bouhemadou, R. Khenata, Structural, electronic and elastic properties of M2SC

719 (M=Ti, Zr, Hf) compounds, Phys. Lett. A, 372 (2008) 6448-6452.

720 [51] S.R. Kulkarni, N.A. Phatak, S.K. Saxena, Y. Fei, J. Hu, High pressure structural

721 behavior and synthesis of Zr2SC, J. Phys.: Condens. Matter, 20 (2008) 135211/135211-

$722 \quad 135211 / 135216$.

723 [52] M.F. Cover, O. Warschkow, M.M.M. Bilek, D.R. McKenzie, A comprehensive survey

724 of M2AX phase elastic properties, J. Phys.: Condens. Matter, 21 (2009) 305403/305401-

$725305403 / 305409$.

726 [53] H. Fu, J. Yang, Z. Zhao, P. Feng, W. Liu, T. Gao, Static compressibility, thermal

727 expansion and elastic anisotropy of Zr2SC single crystals, Solid State Commun., 149 (2009)

$728 \quad 2110-2114$.

729 [54] W. Feng, S. Cui, H. Hu, P. Feng, Z. Zheng, Y. Guo, Z. Gong, First-principles study on

730 electronic structure and elastic properties of hexagonal Zr2SC, Phys. B (Amsterdam, Neth.), 731405 (2010) 4294-4298.

732 [55] M.B. Kanoun, S. Goumri-Said, A.H. Reshak, A.E. Merad, Electro-structural

733 correlations, elastic and optical properties among the nanolaminated ternary carbides Zr2AC,

734 Solid State Sci., 12 (2010) 887-898.

735 [56] S. Cui, D. Wei, H. Hu, Z. Gong, Mechanical instability and ideal strengths of layered

736 M2SC (M = Ti, Zr, and Hf) compounds, J. Appl. Phys. (Melville, NY, U. S.), 113 (2013)

737 083516/083511-083516/083517.

738 [57] M.T. Nasir, M.A. Hadi, S.H. Naqib, F. Parvin, A.K.M.A. Islam, M. Roknuzzaman, M.S.

739 Ali, Zirconium metal-based MAX phases $\mathrm{Zr} 2 \mathrm{AC}(\mathrm{A}=\mathrm{Al}, \mathrm{Si}, \mathrm{P}$ and $\mathrm{S})$ : A first-principles study, Int. J. Mod. Phys. B, 28 (2014) 1550022/1550021-1550022/1550016.

[58] A.C. Ferrari, Raman spectroscopy of graphene and graphite: Disorder, electron-phonon coupling, doping and nonadiabatic effects, Solid State Commun., 143 (2007) 47-57.

743

744

745

746

747

748

749

750

751

752

753

754

755

756

757

758

759

760

[59] R.E. Franklin, The structure of graphitic carbons, Acta Crystallogr., 4 (1951) 253-261.

[60] K.S.W. Sing, D.H. Everett, R.A.W. Haul, L. Moscou, R.A. Pierotti, J. Rouquerol, T.

Siemieniewska, Reporting physisorption data for gas/solid systems, Pure Appl. Chem., 57 (1985) 603-619.

[61] G.L. Drisko, K.M. Chee, N. Scales, A. Ide, E. Sizgek, R.A. Caruso, V. Luca, One-pot preparation and uranyl adsorption properties of hierarchically porous zirconium titanium oxide beads using phase separation processes to vary macropore morphology, Langmuir, 26 (2010) 17581-17588.

[62] M.S.A. Rahaman, A.F. Ismail, A. Mustafa, A review of heat treatment on polyacrylonitrile fiber, Polymer Degradation and Stability, 92 (2007) 1421-1432.

[63] CRC Handbook of Chemistry and Physics, 96th ed., CRC Press, Boca Raton, 2015. [64] C.F. Baes, R.E. Mesmer, The Hydrolysis of Cations, Robert E. Krieger Publishing Company, Inc, Malabar.

[65] M.D. Sacks, C.-A. Wang, Z. Yang, A. Jain, Carbothermal reduction synthesis of nanocrystalline zirconium carbide and hafnium carbide powders using solution-derived precursors, J. Mater. Sci., 39 (2004) 6057-6066.

[66] Q. Peng, J. Guo, Q. Zhang, J. Xiang, B. Liu, A. Zhou, R. Liu, Y. Tian, Unique lead adsorption behavior of activated hydroxyl group in two-dimensional titanium carbide, $\mathrm{J}$ Am Chem Soc, 136 (2014) 4113-4116. 
[67] M. Ghidiu, J. Halim, S. Kota, D. Bish, Y. Gogotsi, M.W. Barsoum, Ion-Exchange and Nuclear Waste Treatment: The First Case Study of Uranium Capture with Vanadium Carbide MXene, ACS Appl. Mater. Interfaces, 8 (2016) 16396-16403. Titanium Carbide for Efficiently Reductive Removal of Highly Toxic Chromium(VI) from Water, ACS Appl. Mater. Interfaces, 7 (2015) 1795-1803.

[70] E.N. Hoffman, D.W. Vinson, R.L. Sindelar, D.J. Tallman, G. Kohse, M.W. Barsoum, MAX phase carbides and nitrides: Properties for future nuclear power plant in-core applications and neutron transmutation analysis, Nucl. Eng. Des., 244 (2012) 17-24. [71] S. Zhao, J. Xue, Y. Wang, Q. Huang, Ab initio study of irradiation tolerance for different Mn+1AXn phases: Ti3SiC2 and Ti3AlC2, J. Appl. Phys. (Melville, NY, U. S.), 115 (2014) 023503/023501-023503/023509.

[72] D.J. Tallman, E.N. Hoffman, E.a.N. Caspi, B.L. Garcia-Diaz, G. Kohse, R.L. Sindelar, M.W. Barsoum, Effect of neutron irradiation on select MAX phases, Acta Mater., 85 (2015) 132-143.

[73] J. Xiao, T. Yang, C. Wang, J. Xue, Y. Wang, Investigations on Radiation Tolerance of Mn+1AXn Phases: Study of Ti3SiC2, Ti3AlC2, Cr2AlC, Cr2GeC, Ti2AlC, and Ti2AlN, J. Am. Ceram. Soc., 98 (2015) 1323-1331.

[74] C. Ang, C. Silva, C. Shih, T. Koyanagi, Y. Katoh, S.J. Zinkle, Anisotropic swelling and microcracking of neutron irradiated Ti3AlC2-Ti5A12C3 materials, Scr. Mater., 114 (2016) 74-78.

[75] D.J. Tallman, L. He, B.L. Garcia-Diaz, E.N. Hoffman, G. Kohse, R.L. Sindelar, M.W. Barsoum, Effect of neutron irradiation on defect evolution in Ti3SiC2 and Ti2AlC, J. Nucl. Mater., 468 (2016) 194-206.

[76] C. Ang, S. Zinkle, C. Shih, C. Silva, N. Cetiner, Y. Katoh, Phase stability, swelling, microstructure and strength of Ti3SiC2-TiC ceramics after low dose neutron irradiation, J. Nucl. Mater., 483 (2017) 44-53.

[77] D.J. Tallman, L. He, J. Gan, E.a.N. Caspi, E.N. Hoffman, M.W. Barsoum, Effects of neutron irradiation of $\mathrm{Ti} 3 \mathrm{SiC} 2$ and $\mathrm{Ti} 3 \mathrm{AlC} 2$ in the $121-1085^{\circ} \mathrm{C}$ temperature range, J. Nucl.

794 Mater., 484 (2017) 120-134.

795 


\section{Figures captions}

798 Fig. 1. Optical microscopy image of $\mathrm{ZrCX}-1$.

799 Fig. 2. (a) Powder XRD patterns. Key: h, hexagonal Zr 2 SC; and (b) Raman spectra of ZrCX-

800 1, representative of $\mathrm{ZrCX}-1$ to -3 .

801 Fig. 3. (a) and (b) SEM images of $\mathrm{ZrCX}-1$ and $\mathrm{ZrCX}-2$ internal fractured surfaces at lower

802 magnification, respectively; (c) and (d) SEM images of the same at higher magnification; (e)

803 nitrogen adsorption-desorption isotherms; and (f) pore size distributions.

804 Fig. 4. Structural evolution of ZrCX-1 with temperature. (a) Powder XRD patterns. Key: t, 805 tetragonal $\mathrm{ZrO}_{2}$; h, hexagonal $\mathrm{Zr}_{2} \mathrm{SC}$; (b) micropore, external and BET surface areas; and (c) 806 in-plane carbon crystallite size.

807 Fig. 5. Adsorption data. (a) Adsorption $\mathrm{pH}$ dependence for $\mathrm{ReO}_{4}{ }^{-}$adsorption onto $\mathrm{ZrCX}-1$

808 and a carbon blank; (b) isotherm data for $\mathrm{ReO}_{4}{ }^{-}$adsorption onto $\mathrm{ZrCX}-1$ at $\mathrm{pH} 5$ with fitted 809 Langmuir and Freundlich models.

810 Fig. 6. STEM studies of Re-loaded ZrCX-1. (a) Bright field image; and corresponding

811 STEM-EDS elemental maps (b-e) of $\mathrm{Zr}, \mathrm{S}, \mathrm{O}$ and $\mathrm{Re}$ distributions. 


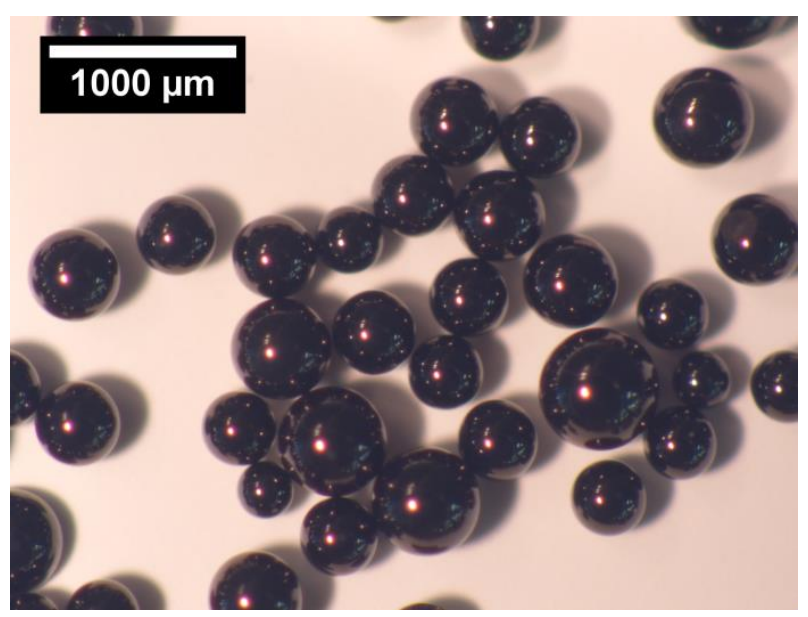

821

Fig. 1. Optical microscopy image of ZrCX-1.

822

823
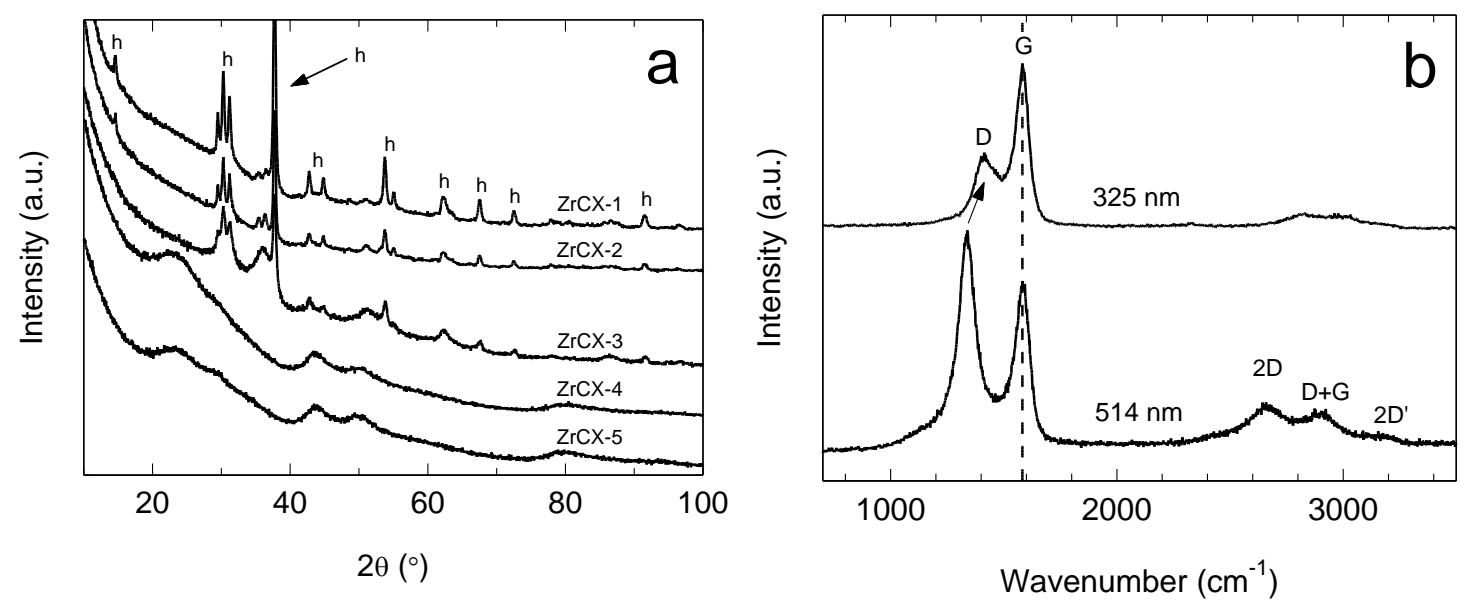

825 Fig. 2. (a) Powder XRD patterns. Key: t, tetragonal $\mathrm{ZrO}_{2}$; h, hexagonal $\mathrm{Zr}_{2} \mathrm{SC}$; and (b) Raman 826 spectra of $\mathrm{ZrCX}-1$, representative of $\mathrm{ZrCX}-1$ to -3 . 

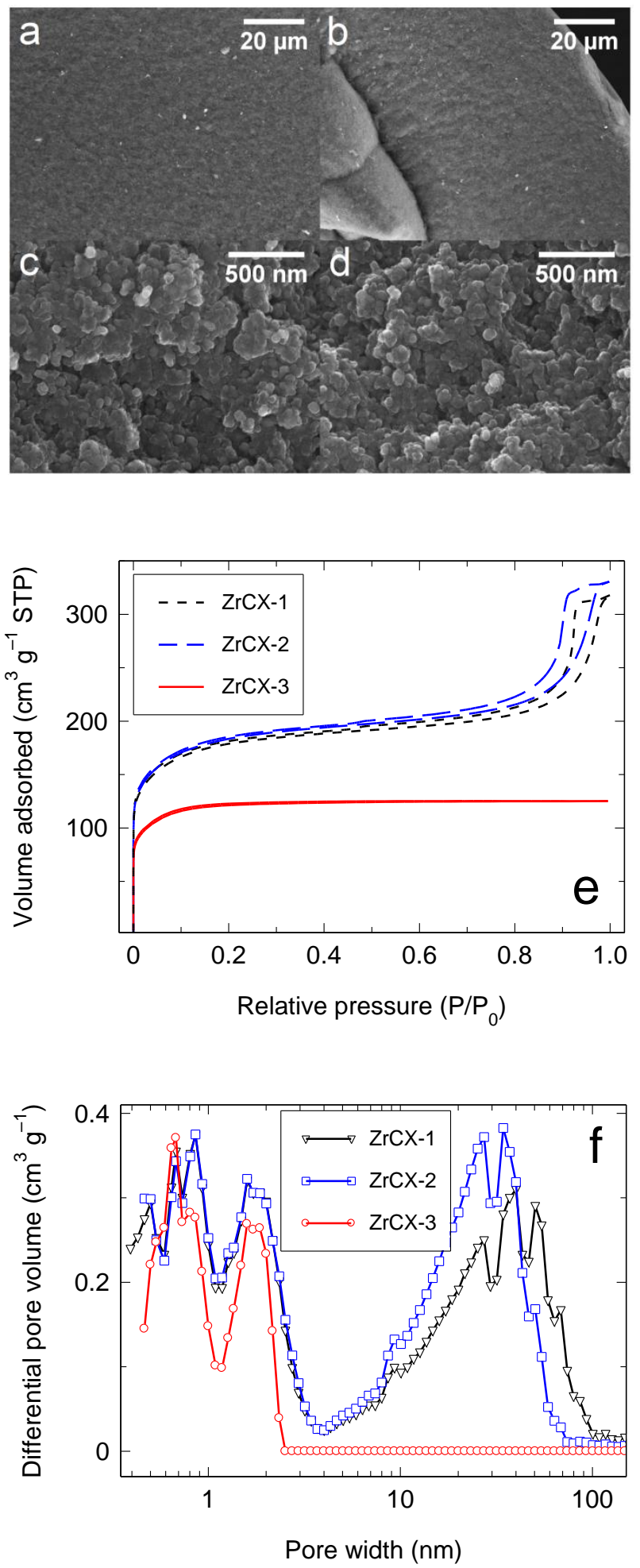

831 Fig. 3. (a) and (b) SEM images of $\mathrm{ZrCX}-1$ and $\mathrm{ZrCX}-2$ internal fractured surfaces at lower 832 magnification, respectively; (c) and (d) SEM images of the same at higher magnification; (e) nitrogen adsorption-desorption isotherms; and (f) pore size distributions. 


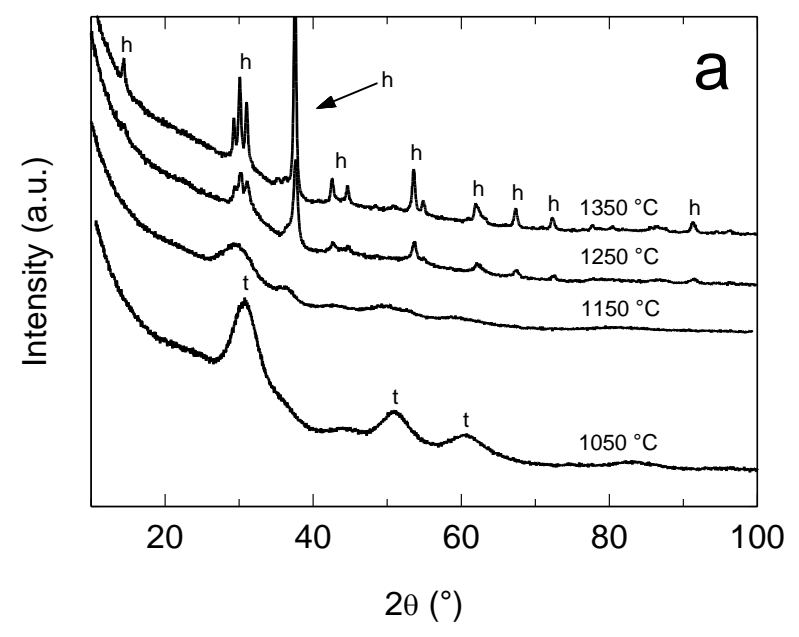

834

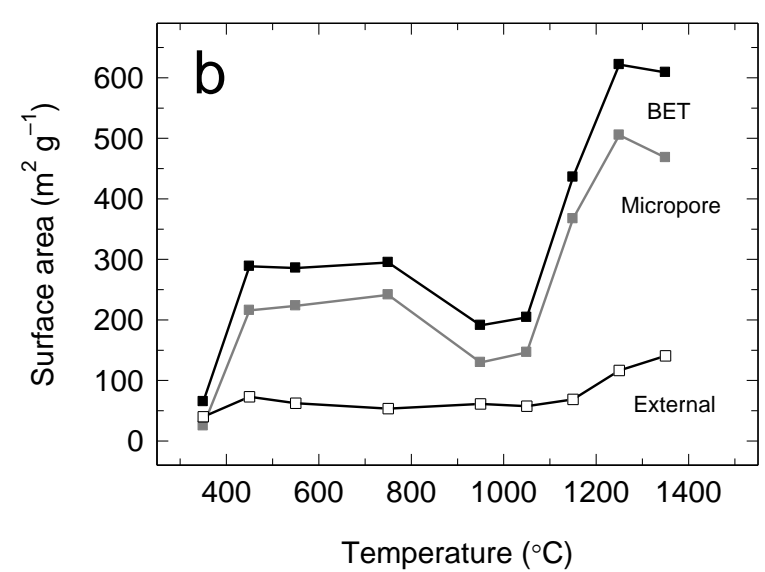

835

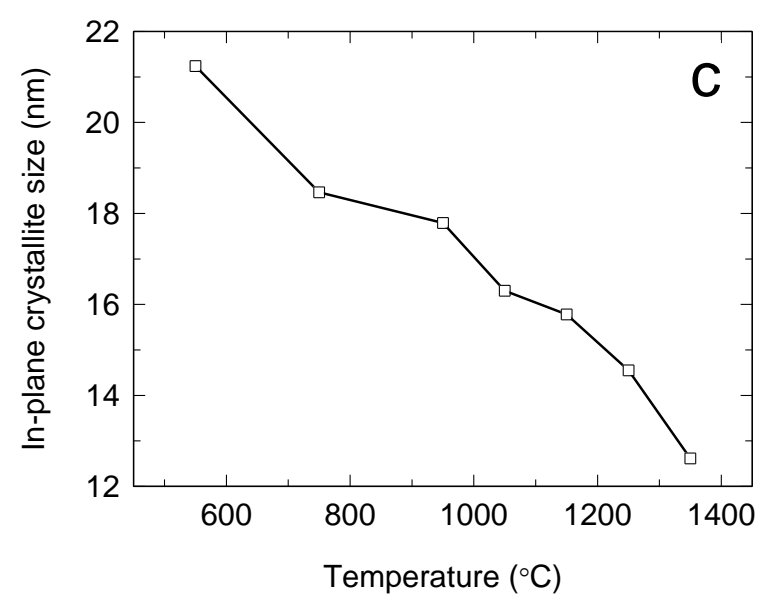

836

837 Fig. 4. Structural evolution of ZrCX-1 with temperature. (a) Powder XRD patterns. Key: t, 838 tetragonal $\mathrm{ZrO}_{2}$; h, hexagonal $\mathrm{Zr}_{2} \mathrm{SC}$; (b) micropore, external and BET surface areas; and (c) in-plane carbon crystallite size. 


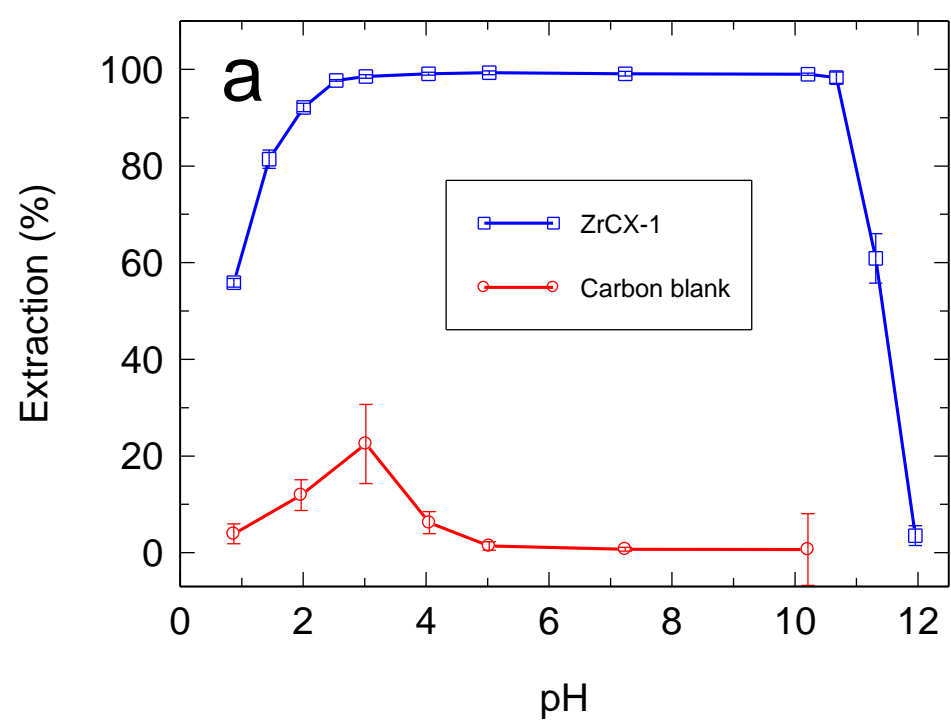

841

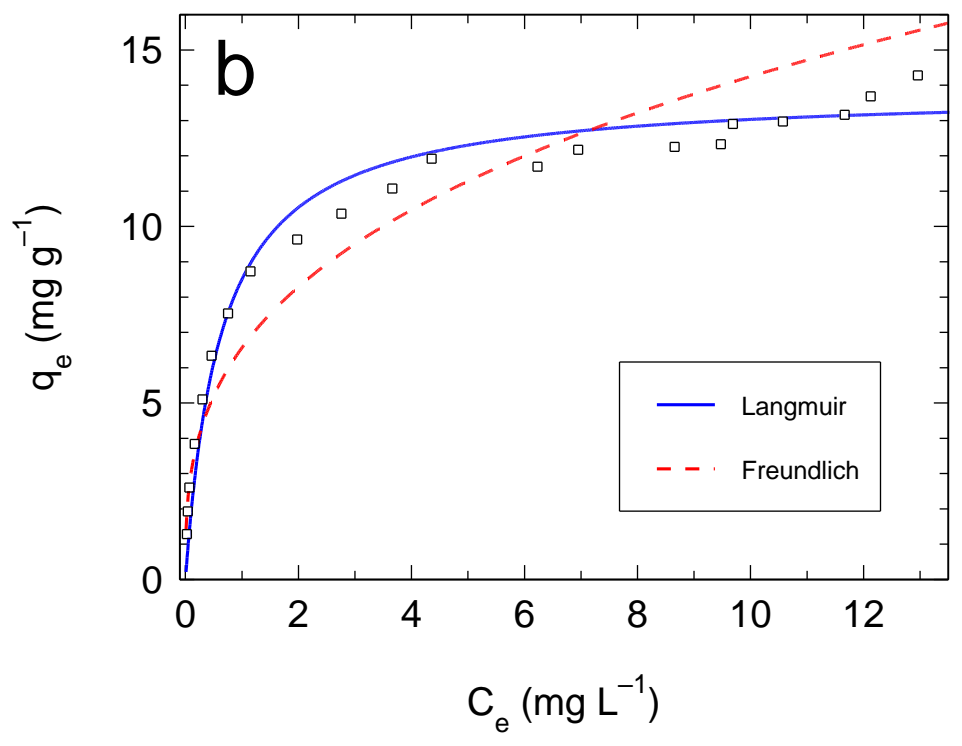

842

843 Fig. 5. Adsorption data. (a) Adsorption $\mathrm{pH}$ dependence for $\mathrm{ReO}_{4}{ }^{-}$adsorption onto $\mathrm{ZrCX}-1$ 844 and a carbon blank; (b) isotherm data for $\mathrm{ReO}_{4}{ }^{-}$adsorption onto $\mathrm{ZrCX}-1$ at pH 5 with fitted 845 Langmuir and Freundlich models. 

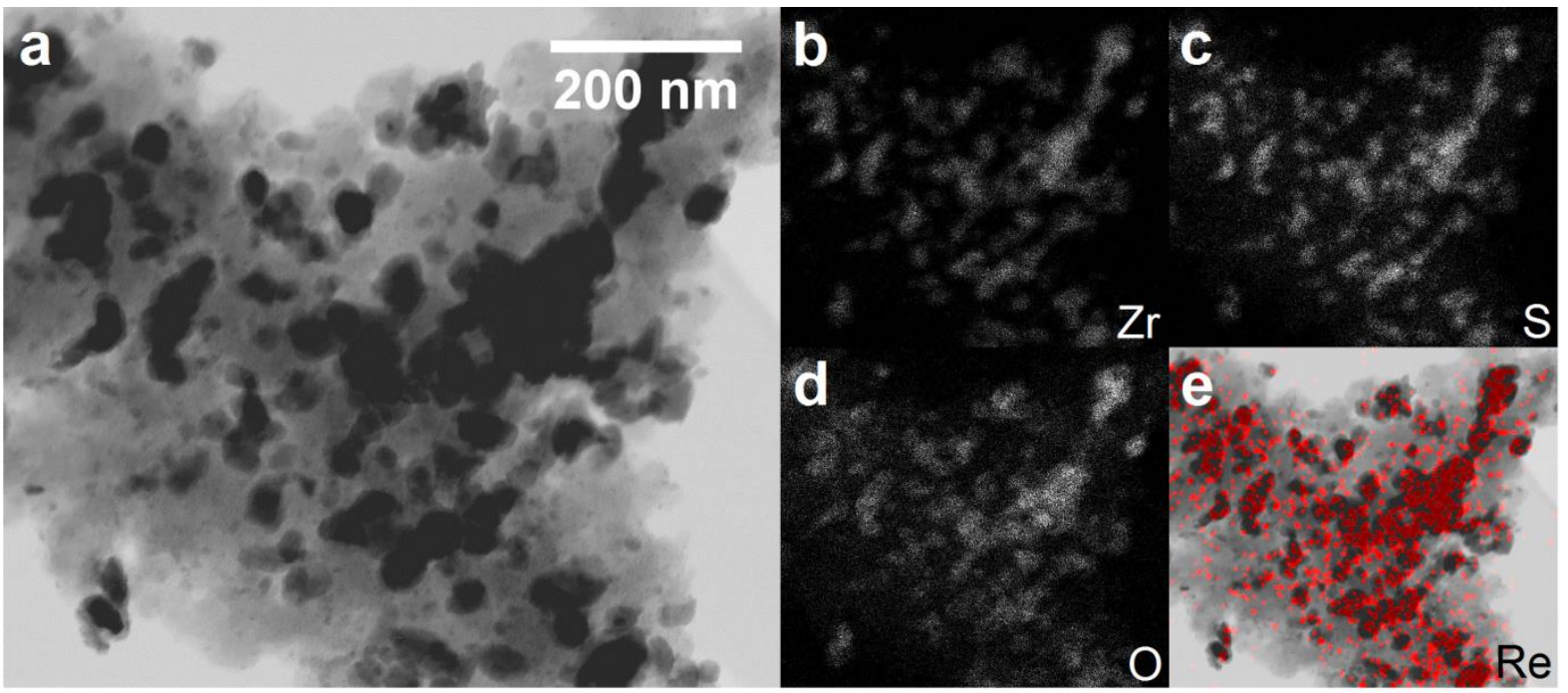

Fig. 6. STEM studies of Re-loaded ZrCX-1. (a) Bright field image; and corresponding 